\title{
Synthesis of Mesoporous Zeolites and Their Opportunities in Heterogeneous Catalysis
}

\author{
Bhupendra Kumar Singh ${ }^{+} \mathbb{D}$, , Yongseok Kim ${ }^{\dagger}$, Seungdon Kwon ${ }^{(D)}$ and Kyungsu Na *(D) \\ Department of Chemistry, Chonnam National University, 77 Yongbong-ro, Buk-gu, Gwangju 61186, Korea; \\ bkchauhan2004@gmail.com (B.K.S.); sandarayong@gmail.com (Y.K.); kwon950515@gmail.com (S.K.) \\ * Correspondence: kyungsu_na@chonnam.ac.kr; Tel.: +82-62-530-3494 \\ + These authors equally contributed to this work.
}

Citation: Singh, B.K.; Kim, Y.; Kwon, S.; Na, K. Synthesis of Mesoporous Zeolites and Their Opportunities in Heterogeneous Catalysis. Catalysts 2021, 11, 1541 https://doi.org/10.3390/catal11121541

Academic Editor: Benoît Louis

Received: 16 November 2021 Accepted: 13 December 2021 Published: 17 December 2021

Publisher's Note: MDPI stays neutral with regard to jurisdictional claims in published maps and institutional affiliations.

Copyright: (C) 2021 by the authors. Licensee MDPI, Basel, Switzerland. This article is an open access article distributed under the terms and conditions of the Creative Commons Attribution (CC BY) license (https:// creativecommons.org/licenses/by/ $4.0 /)$.

\begin{abstract}
Currently, zeolites are one of the most important classes of heterogeneous catalysts in chemical industries owing to their unique structural characteristics such as molecular-scale size/shapeselectivity, heterogenized single catalytic sites in the framework, and excellent stability in harsh industrial processes. However, the microporous structure of conventional zeolite materials limits their applications to small-molecule reactions. To alleviate this problem, mesoporous zeolitic frameworks were developed. In the last few decades, several methods have been developed for the synthesis of mesoporous zeolites; these zeolites have demonstrated greater lifetime and better performance than their bulk microporous counterparts in many catalytic processes, which can be explained by the rapid diffusion of reactant species into the zeolite framework and facile accessibility to bulky molecules through the mesopores. Mesoporous zeolites provide versatile opportunities not only in conventional chemical industries but also in emerging catalysis fields. This review presents many state-of-the-art mesoporous zeolites, discusses various strategies for their synthesis, and details their contributions to catalytic reactions including catalytic cracking, isomerization, alkylation and acylation, alternative fuel synthesis via methanol-to-hydrocarbon (MTH) and Fischer-Tropsch synthesis (FTS) routes, and different fine-chemical syntheses.
\end{abstract}

Keywords: mesoporous zeolite; heterogeneous catalysis; catalytic cracking; isomerization; alkylation and acylation; methanol-to-hydrocarbon; Fischer-Tropsch synthesis

\section{Introduction}

Zeolites are low-density, crystalline microporous aluminosilicates with ordered cavities and channels of molecular dimensions ( 0.3-1 nm). Zeolites are extensively used in the petrochemical industry and various heterogeneous catalysis applications, such as adsorption, separation, and fine-chemical synthesis, among others [1-8]. Furthermore, zeolites have excellent properties, such as high ion-exchange capacity, strong acidic sites, large surface area, high thermal stability, and precisely defined pores and channels [9]. Thus far, 240 zeolite frameworks have been synthesized and documented according to the Structure Commission of the International Zeolite Association (IZA-SC) database [10]. Despite having several advantages, the microporous texture of conventional zeolite catalysts imposes major obstacles on the diffusion of large molecules (branched molecules), thereby decreasing the mass transport of such reagents to intracrystalline active sites [11]. The low transport rate facilitates the conversion of the reactant molecules to undesirable by-products owing to coke formation, which promotes the deactivation of the catalyst [12].

To overcome the limitations of conventional microporous zeolites, scientists have extensively worked on the design and synthesis of various mesoporous zeolites (pore diameter: 2-50 nm) under different physicochemical parameters [13]. The creation of mesopores in zeolites greatly increases the accessible surface area for catalytic reactions involving large molecules and reduces the diffusion path length. The synthetic strategies for mesoporous zeolites can be classified into two major categories: templating approaches 
and post-synthesis treatments [14-17]. Templating approaches can be further divided into hard and soft templating methods. The hard-templating method uses solid templates, such as mesoporous silica or carbon materials, in which suitable precursors are infiltrated and solidified while being confined within the host matrix. Then, the mesoporous zeolites can be obtained as a negative replica of the solid templates that are removed by calcination $[18,19]$. Soft templating can also be further divided into dual templating and multifunctional templating. Dual templating uses zeolite structure-directing agents (SDAs) and a secondary template for the creation of mesoporous zeolites crystals, whereas multifunctional templating combines micropore/mesopore directing moieties within the same template molecule, resulting in hydrophilic (head) and hydrophobic (tail) parts, respectively [20]. In contrast, post-synthesis treatments predominantly use demetallation, that is, dealumination and desilication, using an acid and base, respectively, to synthesize mesoporous zeolites [21]. Thus far, mesoporous zeolites have been synthesized with different pores, shapes, and structural properties; they have been used to promote numerous heterogeneous catalytic reactions and have proven to be very useful in several industrial applications. These zeolites have greatly advanced heterogeneous catalysis owing to their tunable porous networks, a wide spectrum of framework structure, and excellent thermal and structural stabilities [22-26].

This review presents detailed contemporary advances in the design and synthesis of various mesoporous zeolites with a major emphasis on the pioneering examples and recent developments. Section 2 of the review focuses on the synthesis of mesoporous zeolites via templating and post-synthesis approaches, whereas Section 3 is dedicated to their applications in various important heterogeneous catalysis reactions such as catalytic cracking, isomerization, alkylation and acylation, methanol-to-hydrocarbons (MTH) conversion, Fischer-Tropsch synthesis (FTS), and fine-chemical synthesis. Further, the key issues and areas for improvement in the synthetic strategies and applications of mesoporous zeolites have been discussed in the "Conclusions and Perspectives" section.

\section{Synthesis of Mesoporous Zeolites}

Over last few decades, several strategies have been developed for the design and synthesis of mesoporous zeolites of different shapes, sizes, and porosity. This section will discuss the major milestones achieved in the synthesis of mesoporous zeolite via templating methods (hard and soft templating) and post-synthesis treatments (demetallation, such as dealumination and desilication).

\subsection{Templating Approach}

\subsubsection{Hard-Templating Method}

The hard-templating approach uses templates made of solid, rigid-structured materials to facilitate the crystallization of zeolites with a mesoporous morphology [19]. Metal oxides, aerogels, and carbon compounds are used as hard template materials [27]; the hard-templating material is added to the synthesis gel, following which the zeolites occupy and gelate within the interstitial voids created by the hard templates. Subsequent calcination at $\sim 500^{\circ} \mathrm{C}$ generates an open mesoporous zeolite (a negative replica of the template) with a pore size dependent on the diameter of the hard template particles. Initially, nano-zeolites were synthesized using carbon materials, wherein the zeolite synthesis gel was used in the voids of the carbon matrix [28]. Subsequently, a significant study reported on the synthesis of broad mesoporous zeolites (5-50 nm) (Figure 1a,b) using an excess amount of the zeolite synthesis gel owing to the encapsulation of carbon nanoparticles in zeolite crystals [29]. This approach was further extended to successfully synthesize various mesoporous zeolites such as Beta, ZSM-11, ZSM-12, Silicalite-1, Silicalite-2, and $\mathrm{CHA}$, which exhibited significantly better diffusion characteristics and catalytic efficiency than did their conventional bulk microporous counterparts. Further studies demonstrated that templated synthesis using carbon nanotubes and nanofibers provided better control over the shape and size of mesoporous zeolites such as Silicalite-1 (Figure 1c,d) [30] and 
SAPO-34; it also offered an improved catalytic performance in several reactions [31]. Carbon aerogels (CAs), another class of hard templates, were also efficiently used for the synthesis of various hierarchical mesoporous zeolites, such as mesoporous ZSM-5 and FAU, which were synthesized by the sequential $\mathrm{CO}_{2}$ supercritical drying and thermal pyrolysis of resorcinol/formaldehyde gels [32-34]. The mesoporous zeolites synthesized using CA templates displayed a narrow pore size distribution, which could be directly correlated to the thickness of the aerogels used. Moreover, the mesopore diameter could be tuned by altering the carbon/silica molar ratio. Hierarchical ZSM-5 intracrystalline mesoporous single crystals (pore diameter $=12-16 \mathrm{~nm}$ ) were synthesized using am $\mathrm{N}$-doped CA (Figure 2) that was obtained through the hydrothermal carbonization of glucose in the presence of ovalbumin [35]. With the concern of the cost of the template materials, cellulose nanocrystals $(\mathrm{CNCs},<\$ 50$ per $\mathrm{kg}$ ) were used as renewable and sustainable template materials. The inherently high surface area $\left(550 \mathrm{~m}^{2} \mathrm{~g}^{-1}\right)$ and abundant surface hydroxyl groups made CNCs ideal templates in preparing composite materials, which is demonstrated in the synthesis of mesoporous zeolite using CNCs as the mesopore SDA [36].
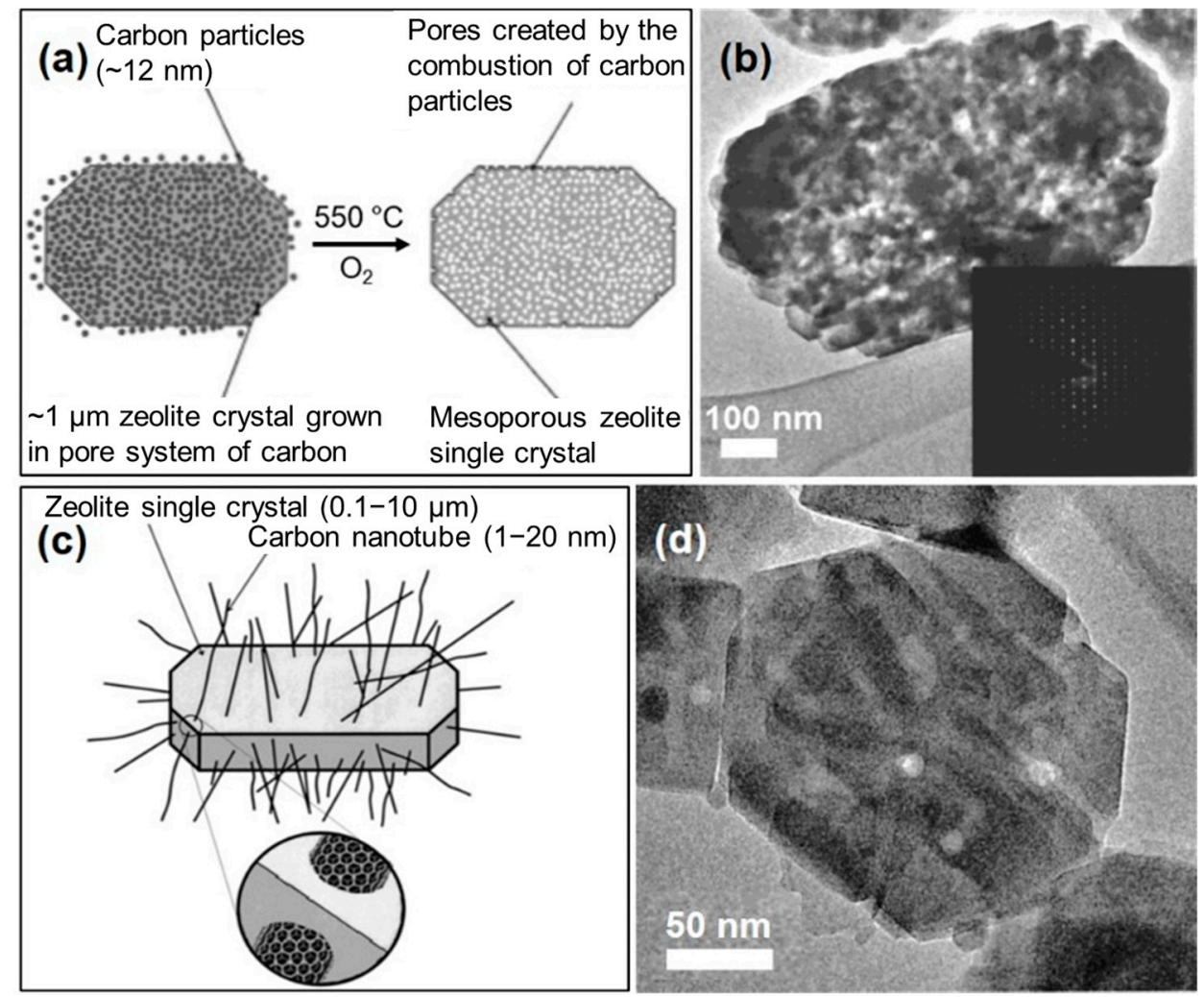

Figure 1. (a) Schematic diagram for the synthesis of mesoporous zeolite crystals using carbon particles. (b) Transmission electron microscope (TEM) image of a mesoporous ZSM-5 single crystal (inset, the electron diffraction pattern) (adapted from reference [29]). (c) Schematic diagram for the synthesis of mesoporous zeolite single crystals using carbon nanotubes. The removal of the nanotubes by calcination leads to the formation of intracrystalline mesoporous zeolites. (d) TEM image of intracrystalline mesoporous silicalite-1 crystal (adapted from reference [30]). 


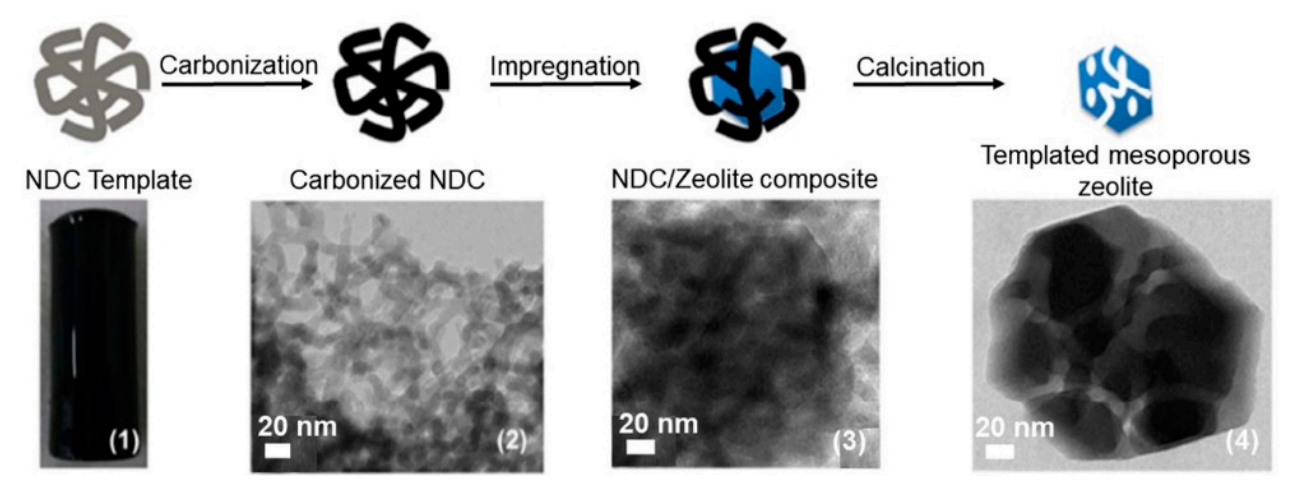

Figure 2. (Top) Schematic diagram for the synthesis of mesoporous zeolite (ZSM-5) from biomassderived nata de coco (NDC) templates. (Bottom) (1) Photograph of NDC template and TEM images of (2) carbonized NDC, (3) NDC/(tetrapropoylammonium hydroxide, TPAOH)-zeolite synthesis by hydrothermal treatment, and (4) templated mesoporous zeolite obtained after calcination (adapted from reference [35]).

Ordered mesoporous carbon, a replica of ordered mesoporous silica, is an important material used in hard templates, and it has been widely used to synthesize various ordered/disordered mesoporous zeolites [37]. The nature of the mesoporous carbon templates determines the pore properties of the synthesized zeolites. Zeolites can be synthesized with tunable porosity, in addition to a bi- or tri-modal porous structure generated using microporous frameworks. Further, mesoporous aluminosilicate molecular sieves have been synthesized using mesoporous carbon molecular sieves (CMKs) and zeolite precursors [38]. The obtained materials were called replicated mesoporous materials (RMMs). Two different mesoporous aluminosilicate molecular sieves, RMM-1 and RMM-3, were synthesized from the CMK-1 and CMK-3 templates with mesoporous structures analogous to the Al-MCM-48 and Al-SBA-15 mesoporous structures, respectively. These materials exhibited better thermochemical properties than did their bulk counterparts. Moreover, an ordered mesoporous aluminosilicate (OMZ-1) with a crystalline-zeolite-pore wall structure was successfully synthesized using CMK-5 template (obtained by the recrystallization of SBA-15) [39]. Due to its high thermal stability, OMZ-1 showed enhanced catalytic efficiency in shape-selective methylation of 2-methylnaphthalene. In another study, a steam-assisted crystallization approach was applied for the synthesis of MFI-type zeolite framework (silicalite-1) with a wide range of crystal morphologies using three-dimensionally-ordered mesoporous (3DOm) carbon templates that were synthesized using size-tunable silica nanoparticle templates $(\sim 10-40 \mathrm{~nm})$ [40]. This work demonstrated the confined crystal growth of intracrystalline mesoporous zeolites (silicalite-1) within the interstitial void space of 3DOm carbon nanobeads. The same group further extended their work to a confined space synthesis of ordered mesoporous BEA, LTA, FAU, and LTL zeolites by applying a conventional hydrothermal treatment on the 3DOm carbon templates (Figure 3) [41]. The authors concluded that the mesoporosity (pore size and structure) in zeolites can be controlled and correlated to the mesopore size of the 3DOm carbon templates. In addition, various morphologies can be obtained by altering the nucleation and crystal growth rates. 


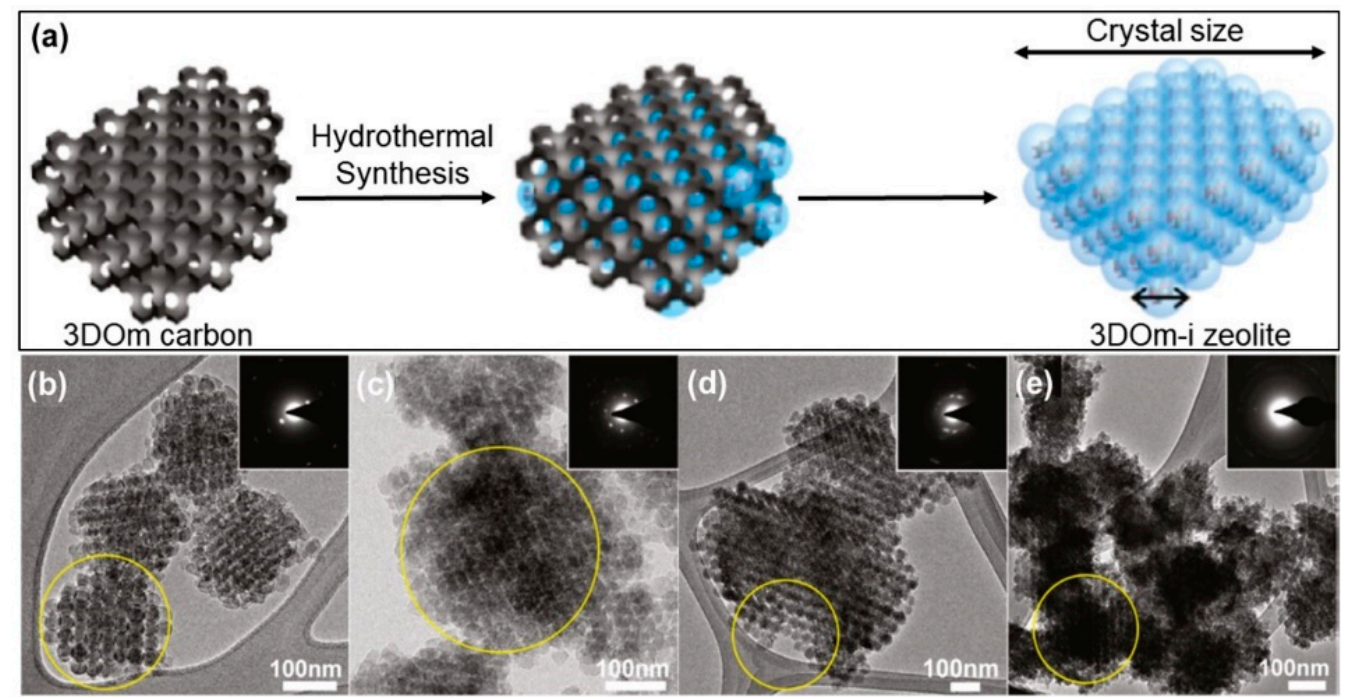

Figure 3. (a) Schematic diagram for the synthesis of three-dimensionally-ordered mesoporousimprinted (3DOm-i) zeolites within the pore voids of 3DOm carbon; (b-e) TEM images along with their electron diffraction patterns from the circled areas (inset images) of 3DOm-i LTA (b), FAU (c), BEA (d), and LTL (e) developed in a $40 \mathrm{~nm}$ 3DOm carbon (adapted from reference [41]).

\subsubsection{Soft-Templating Method}

Soft-templating methods employ a more generalized and flexible approach than hardtemplating methods; organic molecules called SDAs are used along with templates in the synthesis gel to form mesoporous zeolite structures [18,42-44]. Hierarchical mesoporous beta zeolites (pore diameter $=5-40 \mathrm{~nm}$ ) prepared by a one-step hydrothermal reaction using a mixture of small organic ammonium salts and mesoscale cationic polymers exhibited remarkable catalytic performance compared with conventional materials, indicating their potential in industrial applications [45]. Additionally, beta zeolites were prepared using tetraethylammonium hydroxide $(\mathrm{TEAOH})$, a smaller organic template. Furthermore, a mesoporous beta zeolite (Beta-H) was obtained using a dual templating approach in the presence of TEAOH and polydiallyldimethyl ammonium chloride as a mesoscale cationic polymer. This approach for synthesizing zeolites with mesopores is dependent on the type of surfactants; the mesopore diameters are tailorable according to the surfactant tail length or by the addition of hydrophobic swelling agents.

Ryoo's group has accomplished pioneering work in soft-templating synthesis wherein they designed novel bifunctional SDA molecules [46]. A representative surfactant molecule among the studied soft templates is $\mathrm{C}_{22} \mathrm{H}_{45}-\mathrm{N}^{+}\left(\mathrm{CH}_{3}\right)_{2}-\mathrm{C}_{6} \mathrm{H}_{12}-\mathrm{N}_{+}\left(\mathrm{CH}_{3}\right)_{2}-\mathrm{C}_{6} \mathrm{H}_{13}$, which is designated as $\mathrm{C}_{22-6-6}$. The newly designed surfactant molecules comprised both hydrophilic ammonium groups (head) and hydrophobic, long hydrocarbon chains (tail). Similar to conventional SDAs, the hydrophilic parts (quaternary ammonium head groups) directed the formation of microporous crystalline zeolite frameworks, whereas the hydrophobic part (long hydrocarbon tail) facilitated the formation of the mesoporous micellar structure. These bifunctional templates were then successfully applied for the synthesis of mesoporous MFI nanosheets [47]. The concept of using bifunctional templates to create mesoporous zeolitic architecture was a breakthrough, and several studies on zeolites followed. Using this surfactant, ultrathin MFI framework nanosheets were developed along the a-c plane (thickness $=\sim 2 \mathrm{~nm}$ ), which is equal to the b-axis of a single MFI unit cell (Figure 4). The authors proposed that the synthesized mesoporous MFI zeolites comprised three pentasil layers in the a-c plane and one perpendicular channel along the b-axis. These nanosheets can be fabricated into multilamellar or unilamellar mesoporous MFI zeolites, corresponding to the regular or random stacking of the micellar layers, respectively. Owing to the availability of strong acid sites on the external surface, the synthesized mesoporous MFI zeolites exhibited a high efficiency in heterogenous catalysis involving large organic 
molecules. Further studies revealed that the morphology of the mesoporous MFI synthesized using a single alkyl tail template is directly correlated to the initial gel composition and synthesis conditions, as they can alter the arrangement of the lamellae even for similar templates [48]. The authors investigated the morphology of the mesoporous MFI zeolites using $\mathrm{C}_{22^{-} 6^{-6}}$ template under alkaline conditions (in the presence of $\mathrm{Na}^{+}$), which was found to result in randomly assembled unilamellar MFI nanosheets rather than multilayered crystals.
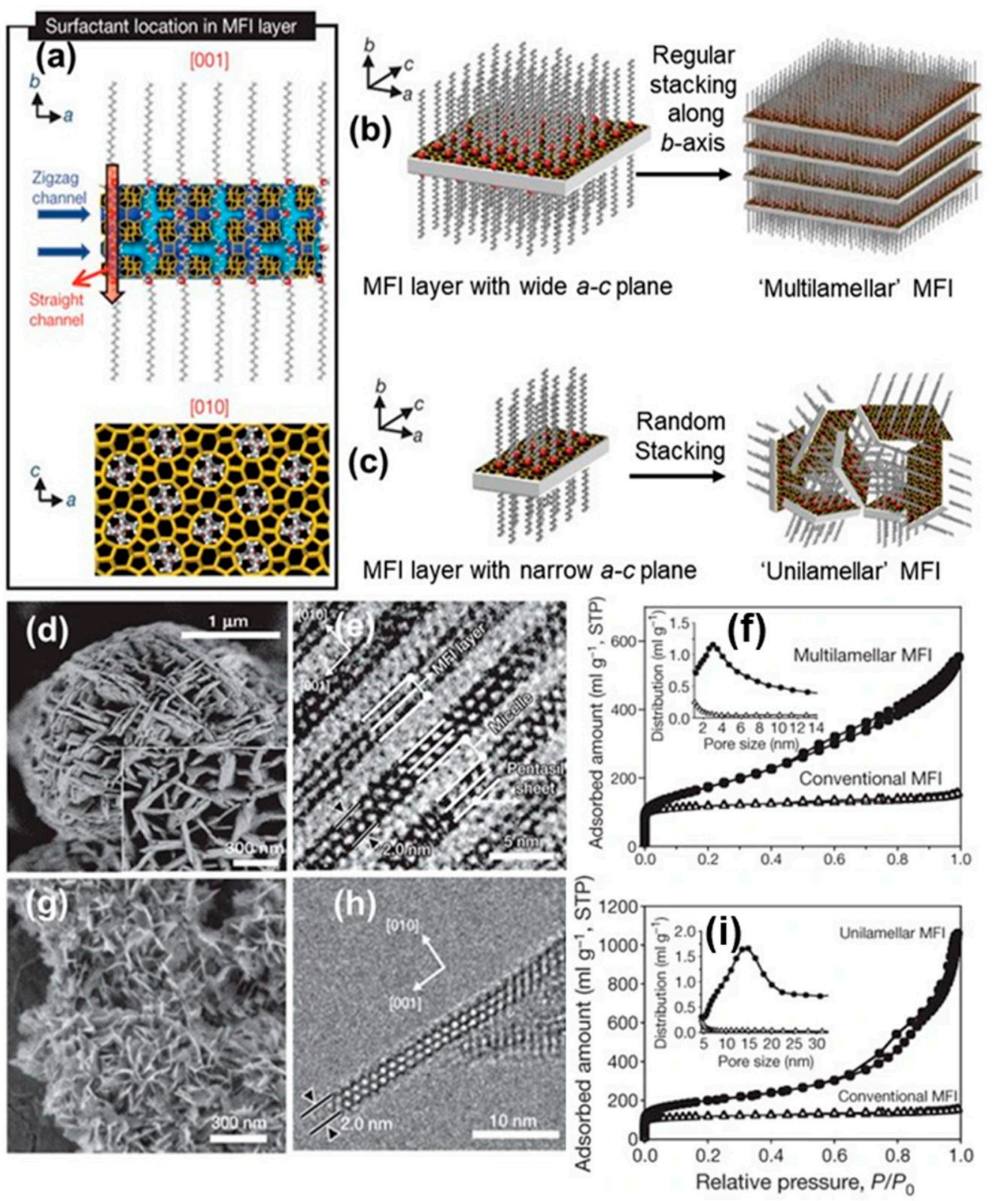

Figure 4. (a-c) Proposed synthesis scheme of mesoporous single MFI nanosheets. (a) The arrangement of template molecules on straight channel c axis (001) and on b-axis (010) in the MFI framework during synthesis. Quaternary ammonium head groups (hydrophilic part) direct the synthesis of MFI nanosheets, while long carbon tails (hydrophobic parts) are responsible for mesopore formation. Multi- and unilamellar MFI nanosheets were obtained due to the regular stacking along b-axis (b) or random stacking (c), respectively; (d-i) SEM, TEM, and $\mathrm{N}_{2}$ adsorption isotherm analysis data of multi- (d-f) and unilamellar (g-i) MFI nanosheets (adapted from reference [47]).

$\mathrm{Na}$ et al. reported breakthrough research on the synthesis of various hexagonal mesoporous molecular sieves (MMS; mesopore range $=2-50 \mathrm{~nm}$ ) containing zeolite-like 
crystalline microporous walls [49]. The syntheses were carried out using newly designed gemini-type SDAs containing a hydrophilic ammonium head group sandwiched between two alkyl chain hydrophobic tails. This gemini-type template was formulated as $\left[\mathrm{C}_{18} \mathrm{H}_{37}-\right.$ $\left.\mathrm{N}^{+}\left(\mathrm{CH}_{3}\right)_{2}-\mathrm{C}_{6} \mathrm{H}_{12}-\mathrm{N}^{+}\left(\mathrm{CH}_{3}\right)_{2}-\mathrm{C}_{6} \mathrm{H}_{12}-\mathrm{N}^{+}\left(\mathrm{CH}_{3}\right)_{2}-\mathrm{C}_{18} \mathrm{H}_{37}\right]\left[\mathrm{Br}^{-}\right]_{3}$ (abbreviated as 18- $\mathrm{N}_{3}-18$ ). Ordered and disordered hexagonal mesoporous structures were created by the aggregation of the templates, and the crystallization of microporous frameworks was accompanied by quaternary ammonium groups (Figure 5). The authors proposed that the wall thickness, framework topology, and mesopore diameter can be altered by using different templates. The synthesized MMSs were found to be highly efficient heterogenous catalysts, especially for the conversion of bulky molecules, when compared with conventional zeolites.

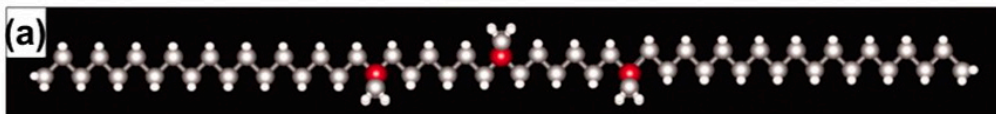

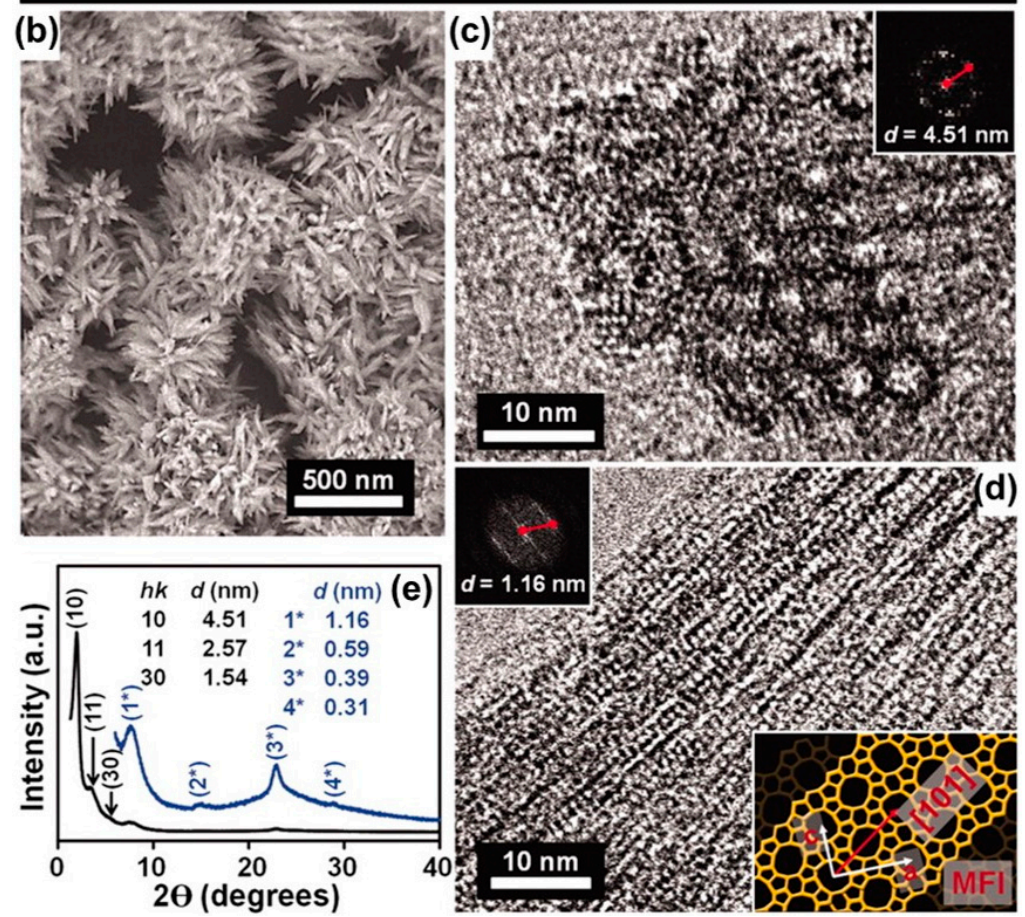

Figure 5. (a) Molecular structure of a gemini-type template $\left[\mathrm{C}_{18} \mathrm{H}_{37}-\mathrm{N}^{+}\left(\mathrm{CH}_{3}\right)_{2}-\mathrm{C}_{6} \mathrm{H}_{12}-\mathrm{N}^{+}\left(\mathrm{CH}_{3}\right)_{2}-\right.$ $\left.\mathrm{C}_{6} \mathrm{H}_{12}-\mathrm{N}^{+}\left(\mathrm{CH}_{3}\right)_{2}-\mathrm{C}_{18} \mathrm{H}_{37}\right]\left[\mathrm{Br}^{-}\right]_{3}\left(18-\mathrm{N}_{3}-18\right)$; the characterization of a hexagonally ordered mesoporous molecular sieve (MMS) by SEM (b), TEM ((c,d), inset FFT patterns), and X-ray diffraction (XRD) (e) (adapted from reference [49]).

Another key development in the soft-templating approach was made by Shunai Che et al., when they developed a series of biphenyl- and naphthyl-based novel templates [50]. They successfully synthesized various mesoporous MFI zeolites (ZSM-5) by introducing biphenyl and naphthyl groups into the alkyl tails of amphiphilic templates with a single quaternary ammonium head group. The $\mathrm{C}_{6} \mathrm{H}_{4}-\mathrm{C}_{4} \mathrm{H}_{3}-\mathrm{O}-\mathrm{C}_{10} \mathrm{H}_{20}-\mathrm{N}^{+}\left(\mathrm{CH}_{3}\right)_{2}-\mathrm{C}_{6} \mathrm{H}_{13}\left(\mathrm{Br}^{-}\right)$ (abbreviated as $\mathrm{C}_{\mathrm{Nh}-10-6}$ ) and $\mathrm{C}_{6} \mathrm{H}_{5}-\mathrm{C}_{6} \mathrm{H}_{4}-\mathrm{O}-\mathrm{C}_{10} \mathrm{H}_{20}-\mathrm{N}^{+}\left(\mathrm{CH}_{3}\right)_{2}-\mathrm{C}_{6} \mathrm{H}_{13}\left(\mathrm{Br}^{-}\right)$(abbreviated as $\mathrm{C}_{\mathrm{Ph}-\mathrm{Ph}-10-6}$ ) facilitated the synthesis of lamellar mesoporous single-crystalline zeolite nanosheets (SCZN-1, Figure 6a-d). Bolaform amphiphilic template molecules containing diquaternary ammonium head groups, such as $\mathrm{C}_{6} \mathrm{H}_{13}-\mathrm{N}^{+}\left(\mathrm{CH}_{3}\right)_{2}-\mathrm{C}_{6} \mathrm{H}_{12}-\mathrm{N}^{+}\left(\mathrm{CH}_{3}\right)_{2}-$ $\left(\mathrm{CH}_{2}\right)_{\mathrm{n}}-\mathrm{O}-\mathrm{C}_{6} \mathrm{H}_{4}-\mathrm{C}_{6} \mathrm{H}_{4}-\mathrm{O}-\left(\mathrm{CH}_{2}\right)_{\mathrm{n}}-\mathrm{N}^{+}\left(\mathrm{CH}_{3}\right)_{2}-\mathrm{C}_{6} \mathrm{H}_{12}-\mathrm{N}^{+}\left(\mathrm{CH}_{3}\right)_{2}-\mathrm{C}_{6} \mathrm{H}_{13}\left(4 \mathrm{Br}^{-}\right)$(denoted as $\mathrm{BC}_{\mathrm{Ph}-\mathrm{n}-6-6}$, where $\mathrm{n}$ represents either $4,6,8$, or 12$)$, directed the synthesis of ZSM-5 nanosheets with a $90^{\circ}$ rotational boundary (SCZN-2, Figure 6e-h). The authors elucidated the role of the strong self-assembling ability and highly ordered arrangement of aromatic groups in stabilizing the lamellar structure (due to $\pi-\pi$ stacking), with a single 
quaternary ammonium head group, which in turn directed the synthesis of SCZN-1. By contrast, the bolaform amphiphilic templates guided a novel hierarchical ZSM-5 (SCZN-2) with $90^{\circ}$ rotational boundary owing to the special branched orientation of the bolaform molecules during crystallization. Further, the same group designed triply branched cationic amphiphilic templates wherein three alkyl chain branches were connected to a benzene ring at 1,3 , and 5 positions, which is $\mathrm{Ph}-\left(\mathrm{O}-\mathrm{C}_{\mathrm{n}} \mathrm{H}_{20}-\mathrm{N}^{+}(\mathrm{Me})_{2}-\mathrm{C}_{6} \mathrm{H}_{12} \mathrm{~N}^{+}(\mathrm{Me})_{2}-\mathrm{C}_{6} \mathrm{H}_{13} \cdot 2 \mathrm{Br}^{-}\right)_{3}$ (denoted as $\mathrm{TC}_{\mathrm{Ph}-\mathrm{n}-6-6,}$ where $\mathrm{n}=10$ and 12) [51]. Interestingly, the carbon chain length of the hydrophobic tail (chains with lengths of 10 and 12 carbons were studied) played a crucial role in the synthesis of different mesoporous ZSM-5 zeolites. The amphiphilic template with a shorter alkyl chain $\left(\mathrm{TC}_{\mathrm{Ph}-10-6-6}\right)$ enabled the synthesis of a sheet-like, singlecrystalline mesoporous ZSM-5 (SCMZ) with a uniform pore thickness of $\sim 2 \mathrm{~nm}$. The lengths of these mesopores were observed to be $\sim 5-50 \mathrm{~nm}$ and $\sim 5-20 \mathrm{~nm}$ along the $\mathrm{c}$ axis and a axis, respectively (Figure $7 \mathrm{a}-\mathrm{d}$ ). By altering the length of the three alkyl chains (from $\mathrm{TC}_{\mathrm{Ph}-10-6-6}$ to $\mathrm{TC}_{\mathrm{Ph}-12-6-6}$ ), a mesoporous ZSM-5 with intercrossed nanosheets (MZIN) was obtained. The synthesized MZIN retained the mesoporous structure after calcination because of the connectivity at the crossed joints (Figure 7e-h). Additionally, these materials were applied in various catalytic reactions, such as the cracking of 1-octene, formation of a diacetal from the acetalization of cyclohexanone with pentaerythritol, and the isomerization of $o$-xylene into $p$-xylene and $m$-xylene. SCMZ exhibited significantly higher catalytic performance compared with MZIN, its conventional counterpart (bulk MFI zeolite).
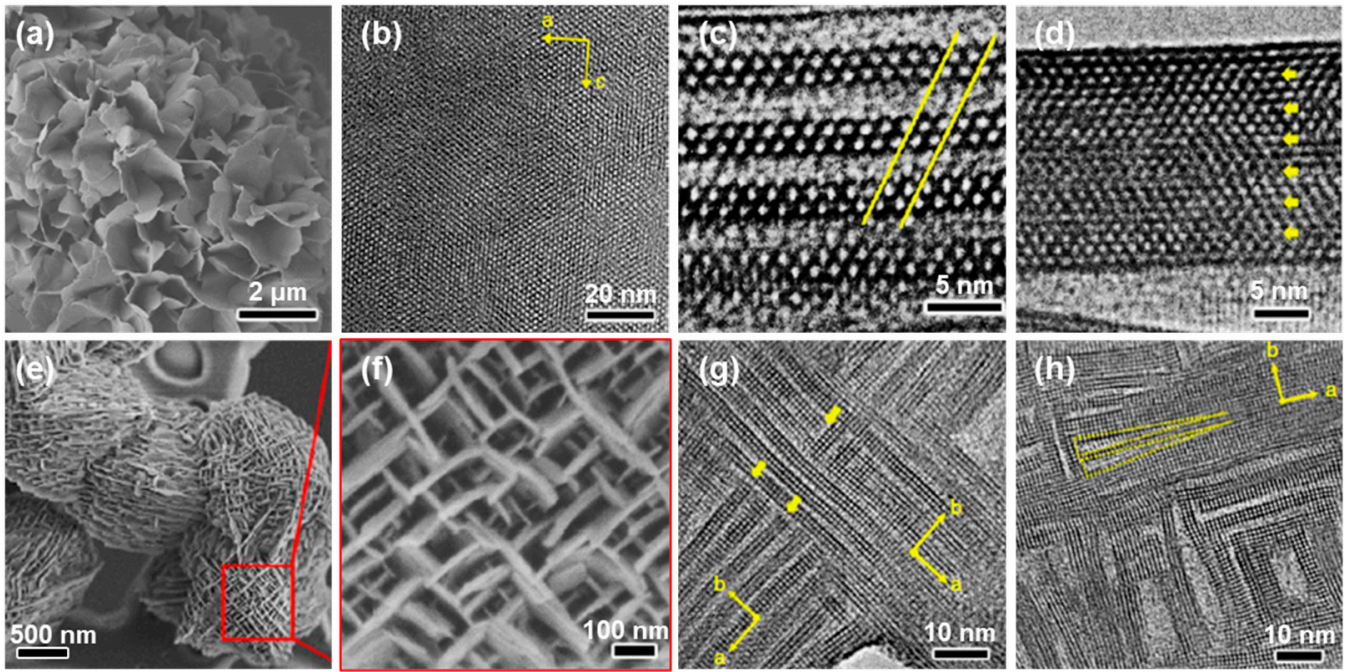

Figure 6. (a-d) Synthesis of lamellar mesoporous single-crystalline zeolite nanosheets (SCZN-1) using the $\mathrm{C}_{\mathrm{Ph}-\mathrm{Ph}-10-6}$ template. (a) SEM and (b,c) high-resolution transmission electron microscope (HRTEM) images along (010) and (100) axes of the synthesized sample. (d) An HRTEM image of the calcined sample along the (100) axis revealed the formation of MFI single crystals. (e,f) SEM and (g,h) HRTEM images of ZSM-5 nanosheets with a $90^{\circ}$ rotational boundary (SCZN-2) synthesized using bolaform amphiphilic templates (adapted from reference [50]). 


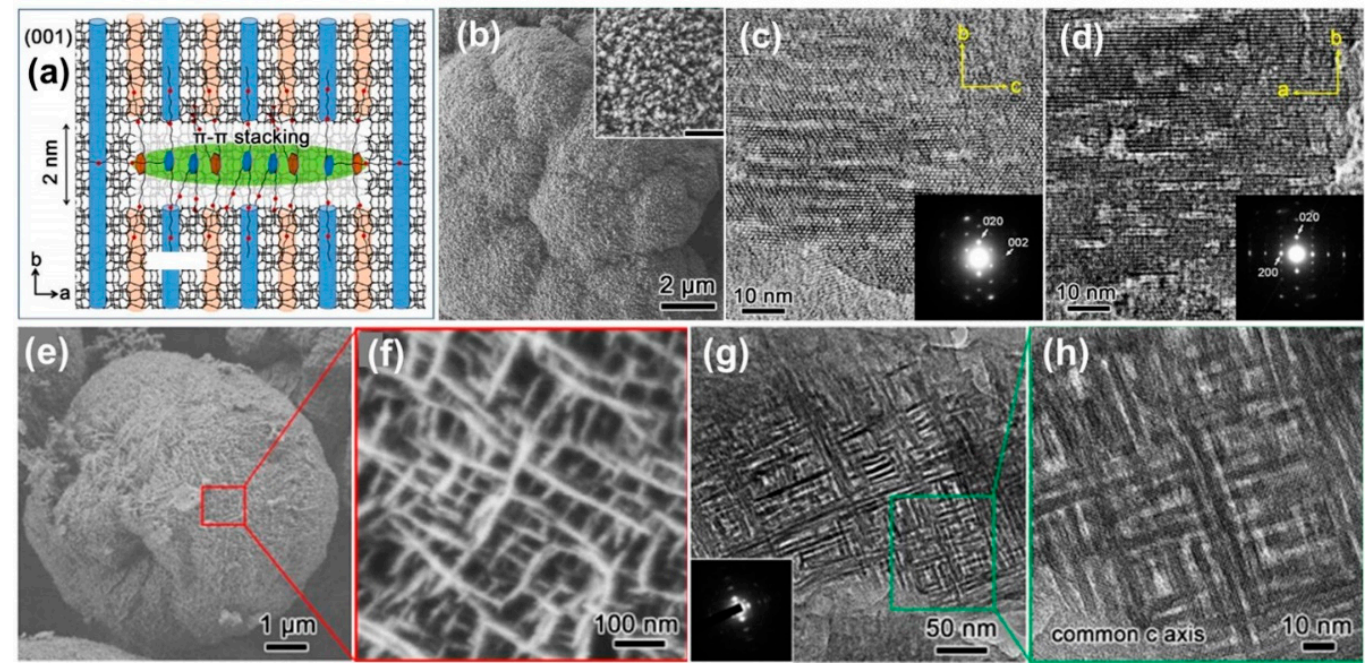

Figure 7. Synthesis of highly stable mesoporous ZSM-5 using triply branched cationic templates. (a) Schematic diagram showing the diquaternary ammonium head groups directing the formation of the ZSM-5 framework along the c axis. (b) SEM image of single-crystalline mesoporous ZSM-5 $(\mathrm{SCMZ})$ (scale bar of inset image $=500 \mathrm{~nm})$. $(\mathbf{c}, \mathbf{d})$ TEM images and their selected-area electron diffraction (SAED) patterns (inset) of SCMZ along different axes. (e,f) SEM images (different magnification) of mesoporous ZSM-5 with intercrossed nanosheets (MZIN). (g,h) TEM images and SAED pattern (inset) of a calcined MZIN along the common c axis (adapted from reference [51]).

Choi et al. reported a synthetic route to a hierarchically meso-/microporous BEA zeolite using a cyclic diammonium (CDM) as an SDA, which led to the pseudomorphic crystallization of the zeolite owing to the suppressed mobility of silicates during crystallization [52]. This hierarchical BEA zeolite exhibited a dramatically improved catalytic lifetime during the isopropylation of naphthalene when compared with its conventional counterpart. The same group extended the technique to the synthesis of MTW and MFI zeolites with nanocrystalline morphologies and intercrystalline mesoporosity using other CDM SDAs [53]. This research demonstrated the influence of the geometry of CDM on the zeolite structure: rigid CDM compounds containing phenyl or biphenyl bridges were found to be very effective SDAs for generating BEA and MTW zeolites having a 12-membered pore channel, whereas a CDM compound connected with two flexible hexamethylene linkages generated an MFI zeolite having a 10-membered pore channel.

\subsection{Post-Synthesis Treatment (Demetallation)}

Unlike the templating methods, the creation of mesopores in zeolites via post-synthesis treatments (demetallation) does not require any template, making it very economical. In demetallation, the synthesis of intracrystalline tetrahedrally occupied framework atoms, such as $\mathrm{Al}$ and $\mathrm{Si}$, are removed from the structure by dealumination and desilication, respectively [54-56].

\subsubsection{Dealumination}

Dealumination denotes the removal of tetrahedrally arranged aluminum atoms from zeolite frameworks using chemical agents or hydrothermal treatment and is frequently regarded as one of the pioneering methods to introduce porosity in zeolites [57]. Initially, dealumination was mainly used in industry to synthesize high $\mathrm{Si} / \mathrm{Al}$ zeolites, but it was later recognized as a facile approach to create mesoporous zeolitic frameworks. Steaming and acid leaching are the common routes for dealumination in zeolites [58]. Diluted inorganic (nitric and hydrochloric acid) and organic acids (oxalate) are commonly used in dealumination. Steam-assisted hydrothermal treatment of zeolites removes aluminum atoms by hydrolyzing the $\mathrm{Si}-\mathrm{O}-\mathrm{Al}$ bonds, which causes the partial breakdown of the frameworks, generating vacancies that cause the formation of mesopores [59]. The meso- 
pore formation is incumbent on the concentration of $\mathrm{Al}$ atoms and their stability in the frameworks during hydrolysis; hence, this approach is more useful for high Al-containing zeolites $(\mathrm{Si} / \mathrm{Al}<10)$. Van Ores' group reported the synthesis of mesoporous beta zeolites via dealumination using steam-assisted hydrothermal $\mathrm{HCl}$ acid treatment at a temperature range of $140-150{ }^{\circ} \mathrm{C}$ for $75 \mathrm{~h}$ [60]. In another study, a mesoporous faujasite (FAU) was synthesized via steam-assisted acid treatment of zeolite $\mathrm{Y}$ with EDTA (ethylenediaminetetraacetic acid) solution in an inert atmosphere [61].

Along with zeolite $Y$, dealumination has been applied to create mesoporous frameworks of other industrially important zeolites, such as beta (BEA), mordenite (MOR), and ferrierite [62]. A series of inorganic acids (nitric, sulfuric, and hydrochloric) and organic acids (acetic, oxalic, and tartaric) at different concentrations were applied for synthesis of mesoporous zeolites via dealumination, and it was revealed that mesopore formation is determined by the nature of the targeted zeolites. For example, under similar conditions, BEA was easier to dealuminate than MOR, while ZSM- 5 was almost unaffected. Despite the potential application of dealumination for synthesizing various mesoporous zeolites, this extra-framework aluminum $\left(\mathrm{EF}_{\mathrm{Al}}\right)$ may be formed along with Lewis acid sites; although these may be useful in some catalytic reactions, they may promote coke formation and cause fast catalyst deactivation. Another concern regarding dealumination is the formation of a random mesoporous structure, which is difficult to control.

\subsubsection{Desilication}

Desilication is another effective post-synthesis treatment for the development of mesoporous zeolites with a high degree of interconnectivity [54] and involves the extraction of $\mathrm{Si}$ atoms from microporous zeolites via alkaline hydrothermal treatment at a temperature range of $50-80^{\circ} \mathrm{C}$. In contrast to dealumination, it does not significantly alter the overall acidity and the crystallinity of the zeolites [63]. Desilication is effective in high-silica zeolites $(\mathrm{Si} / \mathrm{Al}>20)$, and the mesoporous textures mainly depend on the distribution and concentration of $\mathrm{Si}$ atoms within the zeolite frameworks. Ogura et al. reported that the alkaline desilication of commercial ZSM-5 maintained its crystallinity but decreased the micropore volume from 0.177 to $0.133 \mathrm{~cm}^{3} / \mathrm{g}$ while remarkably increasing the mesopore volume from 0.072 to $0.279 \mathrm{~cm}^{3} / \mathrm{g}$ [64]. Groen's group carried out a detailed study on desilication and mesopore generation in various commercial ZSM- 5 zeolites with different $\mathrm{Si} / \mathrm{Al}$ ratio in the range of 50-1000 (Figure 8a) [65]. The authors concluded that high $\mathrm{Si} / \mathrm{Al}$ zeolites usually demonstrated an excessive dissolution of the frameworks, resulting in an uncontrolled and large porous structure. Moreover, the mesopore size in the generated zeolites was found to be $9-10 \mathrm{~nm}$ for a $\mathrm{Si} / \mathrm{Al}$ ratio of 25 to 50 . Zeolites with a high aluminum content $(\mathrm{Si} / \mathrm{Al}<25)$ strongly resist the extraction of $\mathrm{Si}$ atoms from the microporous frameworks.

Pérez-Ramírez et al. made significant contributions to the synthesis of mesoporous high $\mathrm{Si} / \mathrm{Al}$ zeolites, such as ZSM-5, via desilication [66]. They introduced inorganic $\left(\mathrm{Al}(\mathrm{OH})_{4}\right.$ and $\mathrm{Ga}(\mathrm{OH})_{4}$ ) and organic (TPAOH and tetrabutylammonium hydroxide, TBAOH) SDAs to regulate the intracrystalline mesoporosity. They conducted the desilication of ZSM-5 with different $\mathrm{Si} / \mathrm{Al}$ ratios $(17,42$, and 176) in aqueous solutions of TPAOH and TBAOH [67]. Additionally, they compared the catalytic performance of these mesoporous ZSM-5 materials and that of the materials formed by conventional $\mathrm{NaOH}$ leaching. The organic hydroxide-treated zeolites showed better catalytic efficiency for benzene alkylation than parent and NaOH-treated ZSM-5 catalysts. In another work, the concept of the hierarchy factor (HF) was introduced, which is related to the mesopore volume and surface area in the desilicated zeolites. The authors proposed a novel approach for the desilication of ZSM-5 zeolites, involving $\mathrm{NaOH}$ treatment in the presence of quaternary ammonium cations (TPAOH and TBAOH) (Figure 8b,c) [68]. The study concluded that TPAOH and $\mathrm{TBAOH}$ act as pore-growth moderators and increase the HF, which significantly affects the catalytic performance of mesoporous ZSM- 5 in benzene alkylation. Moreover, the addition of either of the two metal complexes, $\mathrm{Al}(\mathrm{OH})_{4}{ }^{-}$and $\mathrm{Ga}(\mathrm{OH})_{4}{ }^{-}$, along with $\mathrm{TPAOH}$ and/or 
TBAOH in the alkaline solution led to the synthesis of mesoporous zeolites with a pore diameter of $5-20 \mathrm{~nm}$. In particular, the alkaline treatment using $\mathrm{Al}(\mathrm{OH})_{4}{ }^{-}$led to the partial integration of aluminum and generated both Lewis and Brønsted acidity.

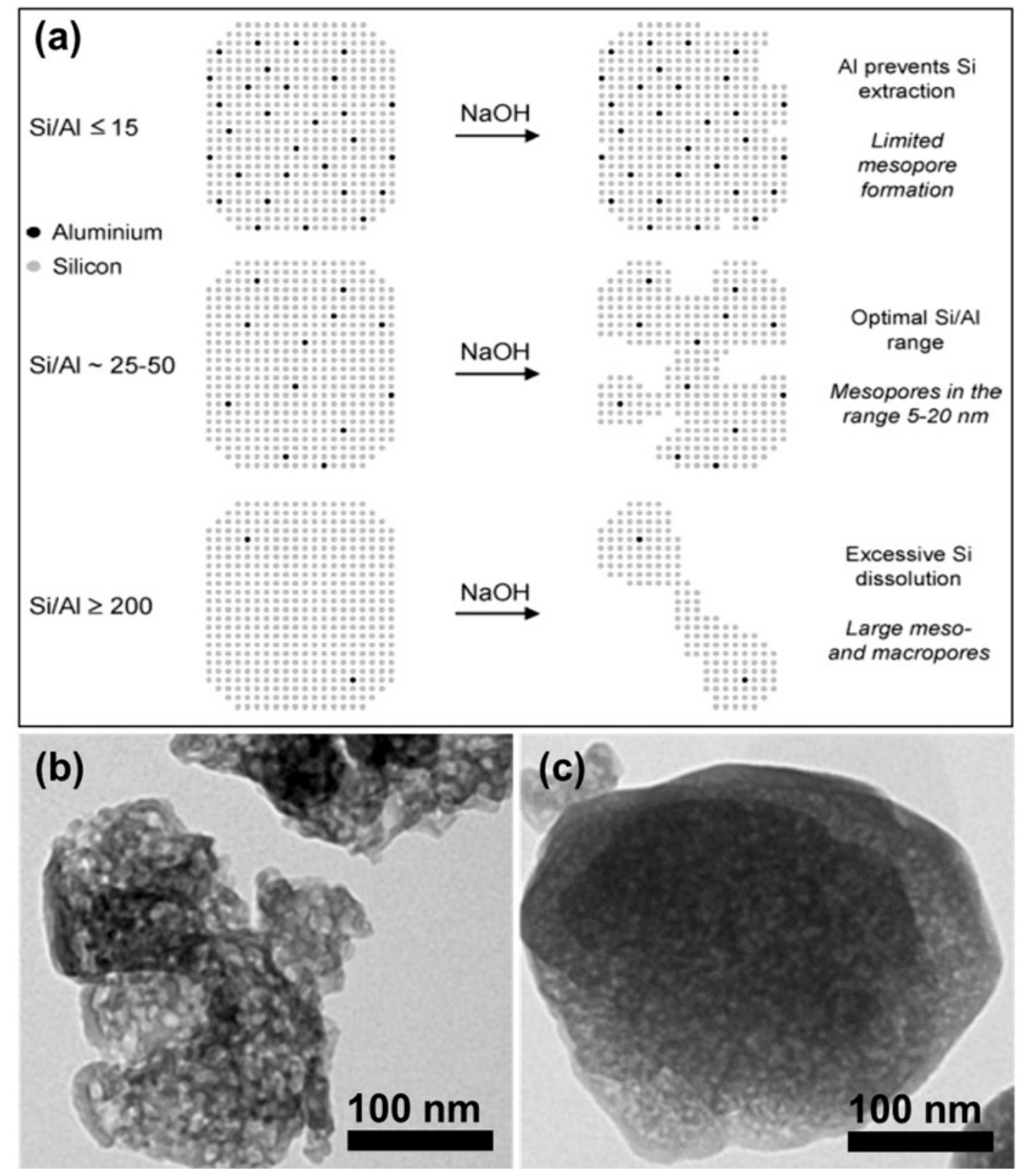

Figure 8. (a) Effect of $\mathrm{Al}$ content on the desilication of MFI-type zeolites in $\mathrm{NaOH}$ solution and a schematic diagram of the mechanism of pore generation (adapted from reference [65]); (b) TEM image of a well-distributed mesoporous ZSM- 5 crystal obtained after pure NaOH treatment; (c) TEM image of mesoporous ZSM-5 synthesized in mixtures of $\mathrm{NaOH}$ and TPAOH solution (adapted from reference [68]).

Desilication is one of the most popular methods to introduce mesoporosity in zeolites. However, the substantial loss of microporosity is a big concern owing to the presence of active sites in micropores, which in turn promotes the loss of the crystalline structure. Desilication mandates a careful consideration of some parameters, such as the concentration of the base solution and the use of additives to achieve the desired mesoporosity while minimizing the loss of microporosity. Moreover, desilication also generates some extraframework aluminum (owing to the re-alumination process) after the alkali treatment, which would require subsequent extraction by ion exchange or acid treatment.

\section{Application of Mesoporous Zeolites in Heterogeneous Catalysis}

Among the various mesoporous zeolites extensively applied as efficient heterogeneous catalysts in various sectors, five zeolites (MOR, zeolite Y, MFI, FER, and BEA) are the most 
important; these are widely applied in the petrochemical industry owing to the presence of strong acidic sites, large surface area, and hydrothermal stability. In this section, we will elucidate the use of mesoporous zeolites in various important reactions, such as catalytic cracking, isomerization, alkylation and acylation, MTH conversion, and FTS.

\subsection{Catalytic Cracking}

Catalytic cracking generates large-scale commodity chemicals [69]. Mesoporous zeolites are widely used in cracking reactions owing to their strong Brønsted acidity, thermal stability, and large surface area, which are necessary for the breaking of stable $\mathrm{C}-\mathrm{C}$ bonds $[70,71]$. Fluid catalytic cracking (FCC) and hydrocracking are especially important owing to the capability of cracking a large quantity of hydrocarbon feedstocks into more valuable fractions. Zeolite $\mathrm{Y}$ is widely used in FCC catalysis owing to its $3 \mathrm{D}$ interconnected micropores and strong acidity [72]. However, to overcome the diffusion limitation and pore size concerns in bulk microporous zeolite $Y$, steam-assisted acid extraction (Section 2.2.1) was used to synthesize a mesoporous zeolite Y (called as USY). Dealuminated USY zeolite demonstrated improved catalytic performance (conversion and enhanced lifetime) in cracking reactions. Additionally, MFI zeolite (ZSM-5) has been applied as an efficient catalyst in several cracking reactions $[73,74]$. Suzuki et al. carried out a comparative study for the cracking of n-octane using mesoporous ZSM-5 and its conventional counterpart (microporous ZSM-5) at $500{ }^{\circ} \mathrm{C}$ [75]. The authors observed that the mesoporous ZSM-5 (synthesized using organosilane template) exhibited lower activity than the conventional ZSM-5. The reduced catalytic activity of mesoporous ZSM-5 was attributed to the decrease in the quantity of acidic sites due to the alkaline treatment. Singh et al. applied highly crystalline mesoporous ZSM-5 zeolites, such as SCMZ and MZIN, for cracking 1-octene over $\sim 20 \mathrm{~h}$ [51]. SCMZ and MZIN zeolites were synthesized via the soft-templating approach using triply branched novel cationic amphiphilic templates (synthesis details are mentioned in Section 2.1.2). The cracking of 1-octene produced ethylene and propylene along with methane, ethane, propane, and butane. For selective recovery of ethylene and propylene, a high reaction temperature $\left(650^{\circ} \mathrm{C}\right)$ was used, as it is established that the selectivity for light olefins increases with the reaction temperature. The authors observed that SCMZ and MZIN maintained a high rate of conversion of 1-octene for up to $\sim 13$ and $\sim 8 \mathrm{~h}$, respectively, whereas it quickly decreased (within $6 \mathrm{~h}$ ) in conventional ZSM-5. Moreover, SCMZ exhibited better catalytic efficiency for 1-octene cracking and the isomeric conversion of $o$-xylene than for the conventional and MZIN zeolites. The superior cracking performance of SCMZ over MZIN was ascribed to the differences in the exposure of different crystallographic faces between SCMZ (along the $a-b$ and $b-c$ planes) and MZIN (restricted along the a-c plane only) zeolites.

Li et al. compared the performance of mesoporous and conventional bulk ZSM-5 in the cracking of 1-hexene [76] and observed that mesoporous ZSM-5 (HZSM-5) showed better catalytic activity than the conventional ZSM-5; they determined the mechanism for the increased catalytic performance (Figure 9). Owing to the complexity of the aromatization and isomerization, 1-hexene was assumed to convert into coke via a long diffusion path (Figure $9 \mathrm{a}$ ). Although the formation of the $\mathrm{C}_{1}-\mathrm{C}_{3}$ products formation was barely affected by the narrowed micropores, the bulk microporous parent material was not suitable for the diffusion of larger molecules. The alkali-treated mesoporous ZSM-5 resolved the diffusion concerns to a great extent (Figure $9 b$ ) and facilitated the conversion of the products over the active sites I-III and IV-VI (readily available) in the mesopores. Therefore, the product formation via aromatization and isomerization were improved with the alkalitreated mesoporous HZSM-5 compared with the microporous parent ZSM-5. Zheng et al. applied a biphasic zeolite composite material for the cracking of n-octane at $500{ }^{\circ} \mathrm{C}$ [77]. Interestingly, the catalyst was composed of two different zeolites: zeolite $\mathrm{Y}$ (core) and beta zeolite (outer layer). The authors compared the cracking data with those of a pure H-Y zeolite and concluded that the composite zeolite achieved much better catalytic conversion (76\%) than the pure H-Y (6\%) and H-Y/H-Beta ( $48 \%$ conversion) zeolites. Christensen et al. 
investigated and compared the performance of mesoporous ZSM-5 single crystals in the catalytic cracking of n-hexadecane with that of their conventional counterparts in acidcatalyzed and slurry-phase reaction conditions; they found that mesoporous HZSM-5 exhibited a conversion $\sim 3$ times $(52 \%)$ higher than that of the conventional microporous HZSM-5 zeolites (17\%) [78]. Moreover, Pt-impregnated ZSM-5 materials displayed highly improved cracking of $n$-hexadecane under similar reaction conditions (n-hexadecane isomerization was enhanced by 4 times in mesoporous zeolites). The authors demonstrated that the activity of ZSM- 5 catalysts can be ordered as follows: mesoporous Pt/HZSM5 > conventional Pt/HZSM-5 > mesoporous HZSM 5 > conventional HZSM-5 >> mesoporous $\mathrm{Pt} /$ silicalite-1 $\sim$ mesoporous silicalite-1. In another work, the catalytic cracking of nhexadecane was investigated over mesoporous ZSM-11, silicalite-2, and titanosilicalite-2, along with the conventional ZSM-5 [79]. All three mesoporous zeolites were synthesized using a carbon matrix. Among them, the mesoporous HZSM-11 zeolites demonstrated the best catalytic performance for the cracking of $n$-hexadecane.

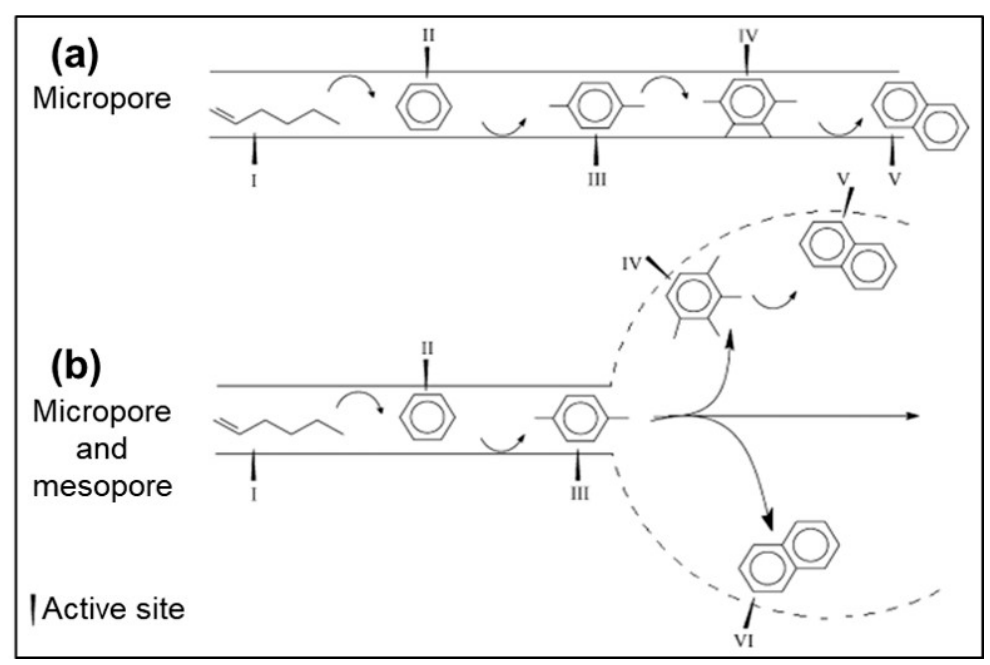

Figure 9. Schematic diagram of the reduced channel blockage of the alkali-treated micro and mesoporous HZSM-5 zeolites. (a) Long diffusion path and occurrence of active sites I-V in microporous zeolite. Coke formation narrows/blocks the micropores, inhibiting the passage of the large molecular aromatics and isomers. (b) Mesoporous zeolites with comparatively shorter diffusion path length facilitate the conversion and selectivity of larger molecules during catalysis (adapted from reference [76]).

A few studies have also demonstrated the catalytic cracking of aromatic molecules over mesoporous zeolites. Lei et al. reported the cracking of 1,3,5-triisopropylbenzene (TIPB) over micro- and mesoporous ZSM-5 [80]. The reaction data revealed the crucial impact of a mesoporous structure in the catalytic cracking of TIPB. The conversion was found to be $14.3 \%$ and $\sim 97.8 \%$ over the microporous and mesoporous HZSM-5 materials, respectively. This observation was explained in terms of the pore size of micro- and mesoporous ZSM-5; the pore diameter in microporous ZSM- 5 was $\sim 0.56 \mathrm{~nm}$, which is less than the diameter of TIPB. Therefore, cracking is only possible on the external surface of microporous ZSM- 5 because TIPB cannot diffuse through ZSM- 5 micropores owing to their small size. In contrast, TIPB can easily diffuse through the mesoporous ZSM-5, which eventually resulted in a remarkable catalytic conversion efficiency of $\sim 98 \%$. Similarly, ZSM-11 and beta zeolites were also applied in the cracking of aromatic molecules, such as 1,3,5-trimethylbenzene and 1,2,4-trimethylbenzene [81]. Both materials demonstrated a higher catalytic performance and a lower rate of deactivation than their conventional (microporous) counterparts, which can be attributed to the facile molecular diffusion in mesoporous zeolites. 


\subsection{Isomerization}

Isomerization is a valuable chemical process wherein a compound is converted to another compound of similar molecular weight but with a different arrangement of atoms and different physical and chemical properties [82]. Zeolites are often used as heterogeneous catalysts in the isomerization of various compounds, such as in the upgrading of naphtha (linear hydrocarbon) into branched products with high octane numbers [83]. Various mesoporous zeolites (such as MFI, MOR, beta, and zeolite $\mathrm{Y}$ ) have been effectively applied in hydroisomerization of n-hexane, n-heptane, n-octane, and n-hexadecane [84-86]. The studies revealed the superior catalytic performance of the mesoporous zeolites when compared to their conventional counterparts. In a remarkable work, mesoporous ZSM-12 and beta zeolites were synthesized using carbon black nanoparticles via sol-gel method with an average mesopore size of approximately $40 \mathrm{~nm}$. These mesoporous zeolites were used in the hydroisomerization of $n$-heptane. The results indicated that mesoporous samples had a catalytic conversion 4 times higher than that of their parent zeolites. Additionally, the selectivity for mono and di-branched isomers can be enhanced by increasing the degree of mesoporosity. Verboekend et al. carried out a comparative study of the hydrodimerization of n-octane on microporous and mesoporous ZSM-22 [87,88]. They observed that the mesoporous ZSM-22 exhibited significantly enhanced catalytic performance and yield of straight-chained isomers compared to the bulk microporous counterpart. Moreover, Ptimpregnated mesoporous ZSM-22 (bifunctional Pt/ZSM-22) displayed better hydrodimerization of n-octane than did microporous parent ZSM-22 (Figure 10a-c). The results were attributed to the large pore size and the decreased diffusion length in mesoporous materials. Somorjai et al. studied the isomerization of $n$-hexane using mesoporous BEA, MFI zeolites, and aluminum-modified mesoporous silica (Al-MCF-17) with and without $\mathrm{Pt}$ nanoparticles. They investigated the contribution of the acidity of each support material to the catalytic performance and selectivity; the acidity of materials was investigated through pyridine adsorption and Fourier-transform-infrared spectroscopy (FT-IR). Pt loaded AlMCF-17 showed the best performance owing to its mild acidity, whereas BEA and MFI zeolites with strong acidity showed undesired cracking and lower selectivity [89]. Qin et al. studied the effect of composite mesoporous structure ( $\mathrm{Y}-\beta$ zeolite) on the hydrocracking and hydroisomerization of n-octane at $280^{\circ} \mathrm{C}$ [90]. Mesoporous Y- $\beta$ zeolite composites exhibited an improved catalytic performance for the hydroisomerization of n-octane. The enhanced catalytic efficiency was explained in terms of the facile diffusion of reactants and products in mesoporous structure. The study was further extended to the hydroisomerization of n-octane by metal-impregnated mesoporous $\mathrm{Y}-\beta$ zeolite composites (Ni-Mo/Y- $\beta$ and $\mathrm{Pt} / \mathrm{Y}-\beta)$. Mesoporous $\mathrm{Ni}-\mathrm{Mo} / \mathrm{Y}-\beta$ and $\mathrm{Pt} / \mathrm{Y}-\beta$ zeolites composite catalysts showed significantly enhanced hydrocracking activity and hydroisomerization performance, which was attributed to the good dispersion of metal particles and the improved accessibility of the acid sites. Pellet et al. applied mesoporous FER zeolite (synthesized via steam-assisted dealumination) for the isomerization of $n$-butene to isobutene [91]. The fresh FER displayed an enhanced n-butene conversion and selectivity for non- $\mathrm{C} 4$ products but resulted in a lower selectivity for isobutene. The deactivation behavior of catalysts was explained by solid-state ${ }^{27} \mathrm{Al}$ MAS NMR analysis and was attributed to the displacement of framework tetrahedral aluminum atoms $\left(\mathrm{F}_{\mathrm{Al}}\right)$ into the extra-framework octahedral aluminum sites $\left(\mathrm{EF}_{\mathrm{Al}}\right)$. Additionally, mesoporous zeolites (e.g., beta zeolite and ITQ-6) were applied for the isomerization of larger hydrocarbons, such as n-hexadecane and linear fatty acids [92,93]. These studies confirm the superior performance of mesoporous materials in the conversion of various useful compounds (isomers) over their microporous counterparts. 

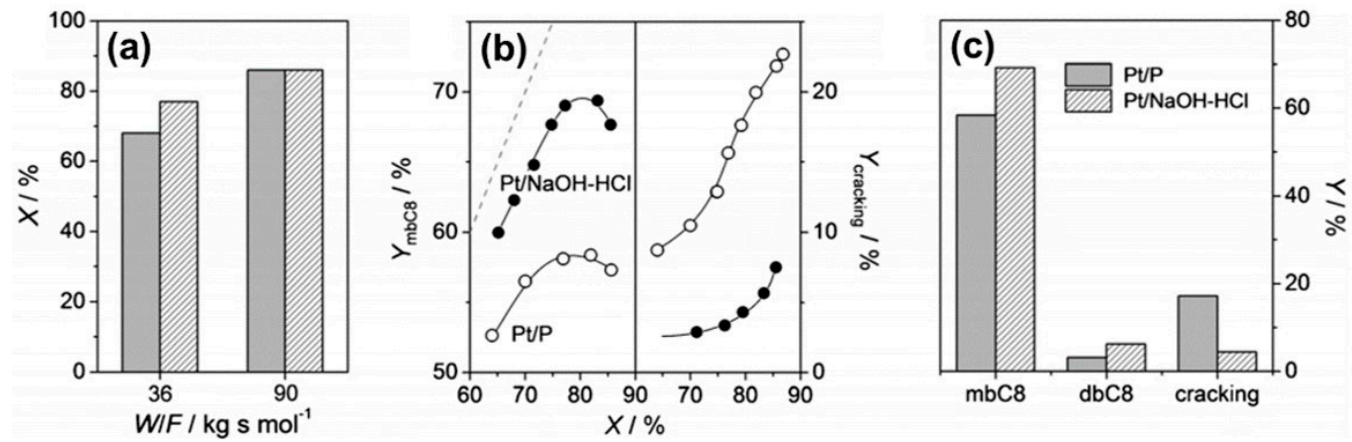

Figure 10. Hydroisomerization of $n_{-} C_{8}$ over the mesoporous bifunctional Pt/ZSM-22 catalyst $\left(\mathrm{T}=573 \mathrm{~K}, P=5 \mathrm{MPa}\right.$, and space time $\left.(W / F)=14-90 \mathrm{~kg} \mathrm{~s} \mathrm{~mol}^{-1}\right),(\mathrm{X}$ and $\mathrm{Y}$ stand for conversion and yield, respectively). (a) Effect of $W / F$ on conversion $\left(\mathrm{PH}_{2}=0.5 \mathrm{MPa}\right.$ for $\mathrm{Pt} / \mathrm{P}$ and $\left.\mathrm{Pt} / \mathrm{NaOH}-\mathrm{HCl}\right)$; (b) the selectivity of monobranched $(\mathrm{mbC} 8)$ and the cracking at different conversion (\%); (c) the selectivity of different products at $80 \%$ conversion, where the di-branched isomers are abbreviated as $\mathrm{dbC} 8$ (adapted from reference [87]).

The isomerization of aromatic hydrocarbons was also conducted over mesoporous MFI-type zeolites. Fernandez et al. studied the effect of mesoporosity and acidic sites in mesoporous ZSM- 5 for $o$-xylene isomerization, wherein intracrystalline mesoporous ZSM-5 (prepared by controlled alkali desilication method) exhibited an enhanced conversion of $o$-xylene to $p$-xylene than did the conventional counterpart owing to the reduced diffusion path [94]. However, a fast deactivation was also observed owing to the coke formation. The deactivation of the catalysts was alleviated by acid treatment ( $\mathrm{HCl}$ washing) of ZSM- 5 . The acid-treated catalysts displayed a two-fold increase in selective isomerization of $o$-xylene to $p$-xylene compared to the parent (bulk microporous) zeolite. Singh et al. presented a comparative study for conversion of $o$-xylene to $m$-xylene and $p$-xylene over synthesized mesoporous ZSM-5 (SCMZ and MZIN) and bulk microporous ZSM-5 [51]. The study revealed that the synthesized mesoporous ZSM- 5 catalysts showed a higher conversion rate of $o$-xylene to its isomers than the microporous ZSM-5. In particular, SCMZ was found to be the most efficient catalyst for conversion of $o$-xylene to $m$-xylene and $p$-xylene and for the selective yield of $m$-xylene, which was attributed to the highly stable intracrystalline mesoporous structure (single-crystalline mesoporous ZSM-5). Mokrzycki et al. reported the application of mesoporous ZSM-5, ZSM-12, MCM-22, and ZSM-12/MCM-41 (synthesized via desilication) for isomerization of terpenes ( $\alpha$-pinene) $[95,96]$. The authors demonstrated that the catalytic isomerization of $\alpha$-pinene over ZSM-5, ZSM-12, and MCM-22 zeolites was largely determined by the degree of alkali desilication. Mesoporous ZSM- 5 (prepared with $0.5 \mathrm{M}$ and $1.0 \mathrm{M} \mathrm{NaOH}$ ) showed better $\alpha$-pinene isomerization than did camphene and limonene. Desilicated ZSM-12 exhibited the highest $\alpha$-pinene conversion $(70 \%)$, whereas ZSM-12/MCM-41 composite catalyst displayed the lowest conversion compared to its conventional counterpart.

\subsection{Alkylation and Acylation Reactions}

The transfer and addition of the alkyl and acyl groups from one molecule to another are called alkylation and acylation reactions, respectively [97]. Zeolites have played a significant role as heterogeneous catalysts in different alkylation and acylation reactions [98,99]. However, their bulk microporous structure limits the diffusion of molecules (reactant and products) and leads to a long diffusion path. Several mesoporous zeolites have been developed to alleviate these issues in alkylation and acylation reactions. Christensen et al. demonstrated the effectiveness of single-crystalline mesoporous MFI zeolites for the alkylation of benzene with ethene [100]. The study revealed that mesoporous MFI single crystals displayed improved catalytic performance when compared with conventional MFI (Figure 11a,b). The authors explained it based on the diffusion path length, which is significantly shorter in mesoporous MFI than in conventional MFI. They also reported 
the synthesis of mesoporous ZSM-5 zeolites (via carbon templating method) and their application in the alkylation of benzene with ethylene to form ethylbenzene at different reaction conditions [101]. Moreover, the catalytic performance of mesoporous ZSM-5 catalysts was observed to be much higher than that of the microporous ZSM- 5 due to the increased diffusion rate through mesoporous frameworks.
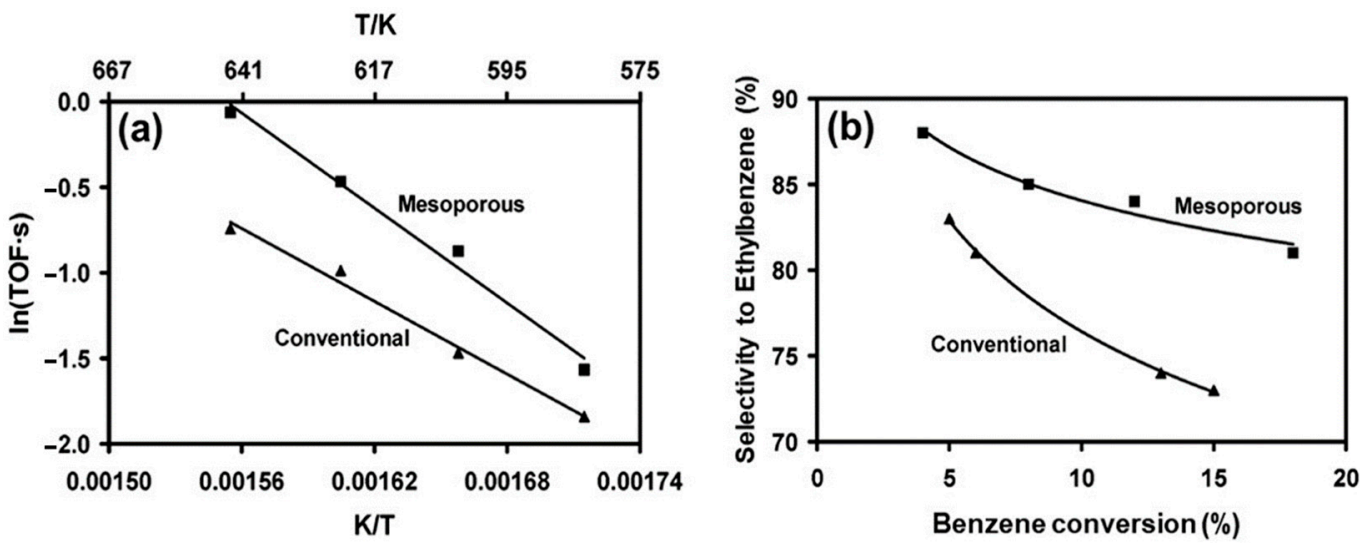

Figure 11. Catalytic performance of mesoporous and conventional MFI zeolites for the alkylation of benzene with ethene. (a) Arrhenius plot representing the activity (in terms of turn-over frequency: TOF) of conventional and mesoporous MFI catalysts; (b) selectivity of ethylbenzene for mesoporous and conventional MFI zeolites in the temperature range of 583-643 K and a pressure of 2.5 bar (adapted from reference [100]).

The alkylation of benzene over mesoporous zeolites has also attracted several research groups. Prins et al. investigated the synthesis of mesoporous ZSM-5 and its application in benzylation of benzene with benzyl alcohol [102]. The authors observed that mesoporous ZSM-5 displayed much higher catalytic performance ( 23 times higher rate constant) than did the conventional material. Their results indicated that the presence of mesopores overcame the diffusion limitations of the microporous zeolite frameworks (Figure 12a,b). Tu et al. reported the application of dealuminated mordenite for the shape-selective ethylation of biphenyl to ethylbiphenyls (EBP), diethylbiphenyls (DEBP), and tri and tetra-ethylbiphenyls (polyethylbiphenyls, PEBP) [103]. In order to compare the structural and pore properties, the study was further extended by including HY zeolite at similar reaction conditions. The data demonstrated the superior catalytic efficiency of mesoporous ZSM- 5 over its bulk microporous counterpart. In another study, Bokhoven et al. synthesized a series of mesoporous mordenites (HMOR) via acid and base leaching as well as soft- and hard-templating methods and applied them in the benzylation of benzene by benzyl alcohol [104]. They demonstrated that the HMOR-1 and HMOR-2 obtained via acid and base leaching exhibited enhanced catalytic performance in the benzylation reaction, which was attributed to the enhancement in the diffusion of large molecules owing to the acid- and base-treated mesopores. 


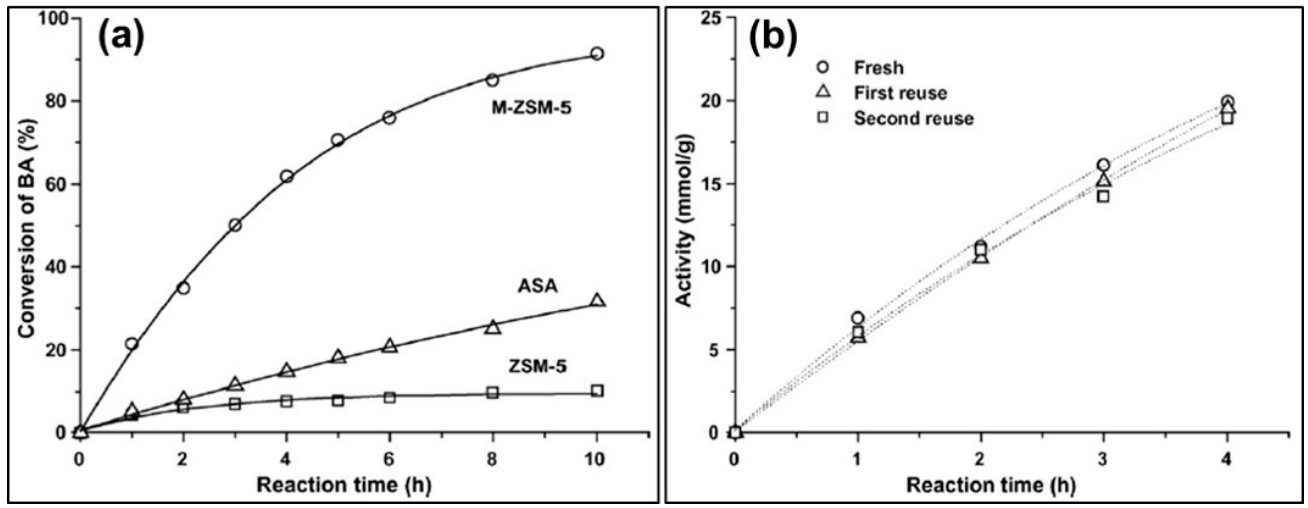

Figure 12. (a) Catalytic performance of mesoporous ZSM-5 (M-ZSM-5), amorphous silica-alumina (ASA), and conventional ZSM- 5 for the benzylation of benzene with benzyl alcohol at $353 \mathrm{~K}$ (catalysts: $0.15 \mathrm{~g}$ for each reaction); (b) recyclability test for M-ZSM-5 catalyst at $353 \mathrm{~K}$ (adapted from reference [102]).

Jin et al. reported the application of mesoporous ZSM-5 (prepared via desilication) for the synthesis of 2,6-dimethylnaphthalene ((2,6-DMN) by methylation of 2-methylnaphthalene (2-MN) [105]. Their study revealed that the catalytic performance and lifetime of mesoporous ZSM-5 was greatly enhanced compared with the parent zeolite (bulk microporous ZSM-5). The conversions of 2-MN were $37 \%$ and $5.3 \%$ with respect to the mesoporous ZSM-5 and parent ZSM-5, respectively, which was attributed to the presence of bigger pores and shorter diffusion paths in mesoporous ZSM-5. Moreover, Zr-treated mesoporous ZSM-5 showed remarkable conversion and selectivity. Singh et al. reported the synthesis of mesoporous mordenite (MOR) and its application in bulky molecular acylation and alkylation reactions, Friedel-Crafts acylation of 1-methoxynaphthalene with benzoic anhydride to form 4-benzoyl1-methoxynaphthalene (BM), and Friedel-Crafts alkylation of benzene with benzyl alcohol to form diphenyl methane (DPM) [106]. The authors also compared the reaction data with the conventional mordenites (CBV 10A and CBV 21). They proposed that the synthesized mesoporous MOR provided suitable diffusion path (pore diameter and length) for the bulky molecules, which eventually resulted in higher catalytic efficiency of mesoporous MOR than that of the bulk microporous materials.

\subsection{Methanol-to-Hydrocarbon (MTH) Conversion}

The catalytic conversion of methanol-to-hydrocarbon is one of the most important applications of zeolites [107-109]. MTH conversion can be categorized as (i) methanolto-olefin (MTO) and (ii) methanol-to-gasoline (MTG), depending on the targeted products [110-116]. Olefins are important components for the petrochemical industry, whereas gasoline is used as a fuel. The MTH reaction has been studied with different types of catalysts and at various reaction conditions. Among various catalytic materials, zeolites have been used in different MTH reactions $[117,118]$. However, the microporous zeolites exhibited rapid deactivation owing to coke formation in their microporous frameworks. A strategy for the reduced formation of coke was developed by the synthesis and application of mesoporous zeolites to various MTH conversion reactions, which demonstrated improved catalytic performance and catalyst lifetime [119]. Through the mesopores, gas phase reactants and products were more easily diffused when compared with the bulk microporous zeolites.

MTH conversion is catalyzed over Brønsted acidic zeolites such as HZSM-5 (MFI-type structure). An MFI-type framework with pore dimensions of $0.56 \mathrm{~nm} \times 0.53 \mathrm{~nm}$ is suitable for the production of gasoline-range hydrocarbons. Recently, hierarchical ZSM-5 was widely applied in MTH conversion. Kim et al. reported the improvement of catalytic lifetime of mesoporous zeolites owing to the facile diffusion of coke precursor from the active sites of micropores to the large external space of mesopores (Figure 13) [120]. Schmidt et al. reported differences in the deactivation/reactivation behaviors of microporous and hierar- 
chical ZSM-5 attributed to the difference in porosity, which in turn caused a difference in the coke formation location [121]. Diverse combinations of mesopore-generating templates were investigated to optimize the porosity, which led to a huge change in the catalytic performance. Attempts to modify the hierarchical ZSM- 5 by adding various elements were also reported. Ni et al. synthesized mesoporous $\mathrm{Zn} / \mathrm{ZSM}-5$ via $\mathrm{Zn}$-impregnation on mesoporous ZSM-5, which led to improved catalytic performance (lifetime and hydrocarbon selectivity) [122]. Wang et al. also reported the synthesis and application of mesoporous Zn/ZSM-5 (crystals size in nanoscale range) and achieved enhanced catalytic activity and liquid hydrocarbon selectivity by controlling the diffusion length of mesoporous ZSM-5 [123]. Mentzel et al. synthesized H-Ga-MFI (Ga was used in place of $\mathrm{Al}$ ) and revealed that the presence of Ga in MFI framework reduced the acidity of the individual active sites compared to H-ZSM-5 [124]. As a result, only an insignificant amount of coke was produced. Meng et al. presented a detailed study on the influence of substitution of framework atoms in MFI-type zeolites by $\mathrm{Al}^{3+}, \mathrm{Ga}^{3+}, \mathrm{Fe}^{3+}$, and $\mathrm{B}^{3+}$ ions and the subsequent effect on MTH reactions [125]. Substitution of framework atoms caused a significant acidity difference in MFI zeolites and exhibited a distinct catalytic performance according to the substituents. Goodarzi et al. introduced an inert porous shell (silicate-1, $15 \mathrm{~nm}$ thickness) to protect the surface of acidic zeolite from the coke formation, which showed improvement in catalytic lifetime [126].

Silicoaluminophosphate (SAPO) is one the most used zeolite materials and is highly applicable in various catalytic reactions. The SAPO-34 zeolite (CHA-type structure) displays high catalytic efficiency due to its moderate acidity and large cavities $(0.94 \mathrm{~nm})$ that are connected by an eight-membered ring pore $(0.38 \mathrm{~nm} \times 0.38 \mathrm{~nm})$ [127]. However, with the formation of coke, the eight -membered rings restrict the diffusion of molecules from the cavities. The introduction of large pores in the SAPO-34 to suppress the coke formation and to improve the diffusion of molecules was investigated by Liu et al. [128]. In this study, the authors synthesized hierarchical SAPO-34 with tri-level inter-crystalline porous structure (micro-meso-macropore). Enhancement of mass transport within the tri-level porous system resulted to a higher catalytic lifetime when compared with the conventional microporous SAPO-34 catalyst. Jin et al. prepared well-organized mesoporous hierarchical SAPO-34 catalyst via desilication ( $\mathrm{Si}$ atoms were extracted by citric acid) [129]. The hierarchical mesoporous SAPO-34 catalyst exhibited prolonged lifetime and selectivity for ethylene and propylene. Furthermore, Liu et al. reported the synthesis of mesoporous SAPO-34 via dealumination (using oxalic acid) and its application in MTH reactions [130]. The designed mesoporous SAPO-34 showed improved catalytic lifetime than did the commercial zeolites.

\subsection{Fischer-Tropsch Synthesis (FTS)}

FTS has attracted widespread attention owing to its application in the transformation of syngas $\left(\mathrm{CO} / \mathrm{H}_{2}\right)$ into ultraclean hydrocarbon fuels and value-added chemicals [131-133]. Materials based on transition metals such as $\mathrm{Co}$ and Fe are often used in the industrial application of FTS [134-137]. Ru and Ni are used for FTS as alternative metals. However, $\mathrm{Ru}$ is too expensive and Ni produces excess methane, which is undesirable $[138,139]$. Recent studies demonstrated tunable selectivity in FTS by combining different metals with zeolites and maximized the production of the desired products and overcame the AndersonSchultz-Flory (ASF) limitations (a statistical distribution determined by the chain-growth probability factor) to obtain isoparaffins in middle-distillate products $\left(\mathrm{C}_{10-20}\right)$. However, the rapid coke deposition during the hydrocracking reactions blocks the active sites and decreases the reactivity gradually. To overcome the coke deposition and facilitate faster deactivation concerns, mesoporous zeolites have been widely applied as ideal supporting materials for several metals used in the FTS reaction $[140,141]$. 

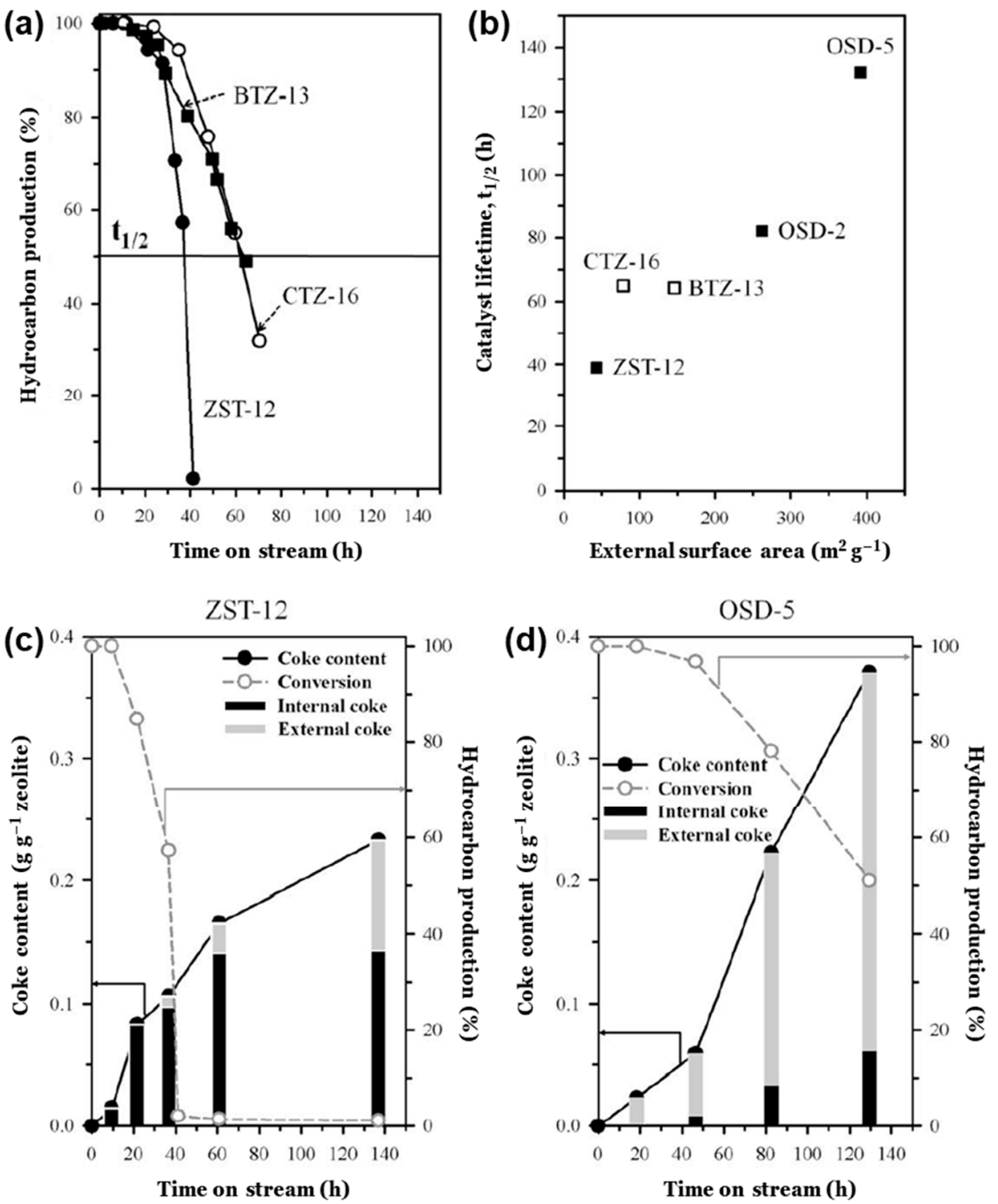

Figure 13. Catalytic performance of conventional MFI (ZST-12, $\mathrm{Si} / \mathrm{Al}=\sim 12)$ and mesoporous MFI (base-treated zeolite (BTZ-13, $\mathrm{Si} / \mathrm{Al}=\sim 13)$, carbon-templated zeolite $(\mathrm{CTZ}-16, \mathrm{Si} / \mathrm{Al}=\sim 16)$, and organosilane-directed (OSD-2, $\mathrm{Si} / \mathrm{Al}=\sim 13.7$ and $\mathrm{OSD}-5, \mathrm{Si} / \mathrm{Al}=\sim 13$ ); 2 and 5 refer to the number of 3-[(trimethoxysilyl)propyl]hexadecyldimethylammonium chloride (TPHAC) moles) zeolites for methanol-to-hydrocarbons (MTH) conversion. (a) MTH conversion over ZST-12, BTZ-13, and CTZ-16; (b) correlation between catalyst lifetime and external surface areas of different catalysts; coke formation on bulk microporous ZST-12 (c), and mesoporous OSD-5 (d) catalysts (adapted from reference [120]).

Peng et al. synthesized Co-supported mesoporous $\mathrm{H}-\mathrm{Y}$ and Na-Y zeolites using a sequential dealumination and desilication method to study the influence of the size of cobalt nanoparticles and the mesopores of supporting materials on the activity and selectivity [142]. Co/Na-meso-Y catalysts with mean cobalt particle sizes in the range of 4.9-27.0 nm resulted in a varied product selectivity along with slight changes in CO conversion (Figure 14a), whereas a large mean cobalt size led to higher $C_{21+}$ selectivity. The increase in mesopore size accelerated the mass transport and suppressed the successive demethylation (Figure 14b). Therefore, the mesopores may have contributed to tuning the FTS product selectivity by influencing the degree of successive demethylation of the heavier primary hydrocarbons. $\mathrm{C}_{10-20}$ selectivity of about $60 \%$ has been achieved over a Co/Na-meso-Y catalyst containing $8.4 \mathrm{~nm}$ Co particles and $15 \mathrm{~nm}$ mesoporous 
structure (Figure 14c). Zhao et al. synthesized Co-supported mesoporous ZSM-5 using a soft-templating approach. The synthesized mesoporous materials had different $\mathrm{Si} / \mathrm{Al}$ ratios of 60,80 , and 120 and showed different catalytic reactivity and selectivity [143]. $\mathrm{Co} /$ Meso-ZSM-5 $(\mathrm{Si} / \mathrm{Al}=60)$ showed better selectivity to $\mathrm{C}_{5-18}$ hydrocarbons $(61.7 \%)$ and higher olefin/paraffin ratio (0.68), which was attributed to the small size of the Co particles and large number of weak acidic sites. For the Co/Meso-ZSM-5 $(\mathrm{Si} / \mathrm{Al}=120)$ catalyst, the reducibility of Co particles was enhanced, and the concentration of weak acid sites was reduced, which led to a higher $\mathrm{CO}$ conversion (67.5\%) and $\mathrm{C}_{18}{ }^{+}$selectivity (12.6\%). Sartipi et al. synthesized Co-supported mesoporous ZSM-5 via alkaline treatment with $1 \mathrm{M}$ $\mathrm{NaOH}$ solution (mesoH-ZSM-5(a)) and organic base TPAOH as desilication agent (mesoHZSM5(o)) [144]. The FTS results showed that the catalytic activities of Co/meso-H-ZSM-5(o) $(\sim 90 \%)$ and Co/meso-H-ZSM-5(a) ( $~ 80 \%)$ were higher than those of microporous Co/HZSM-5 ( 65\%) after $20 \mathrm{~h}$ reaction. This selectivity improvement over Co/mesoH-ZSM-5(a) was attributed to the reduced diffusion length, which eliminated the overexposure of the FT hydrocarbons to strong acid sites. Kim et al. synthesized nanosponge-like mesoporous MFI zeolite as a supporting material for cobalt nanoparticles [145]. The authors demonstrated FTS reaction over mesoporous Co/MFI nanosponge and compared the results with bulk $\mathrm{Co} / \mathrm{MFI}$ (microporous) and alumina-based catalysts (Figure 14d). Mesoporous Co/MFI exhibited high catalytic performance (CO conversion $\sim 82 \%$ ) and long catalytic lifetime (after $200 \mathrm{~h}, \sim 74 \%$ ) in FTS reaction.

(a)

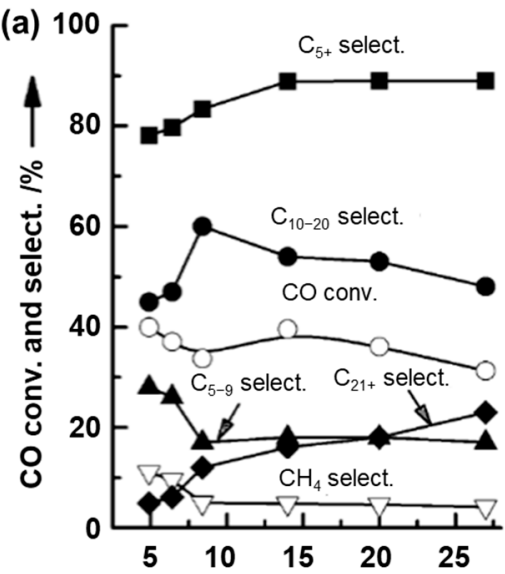

Co particle size $/ \mathrm{nm} \longrightarrow$

(c)

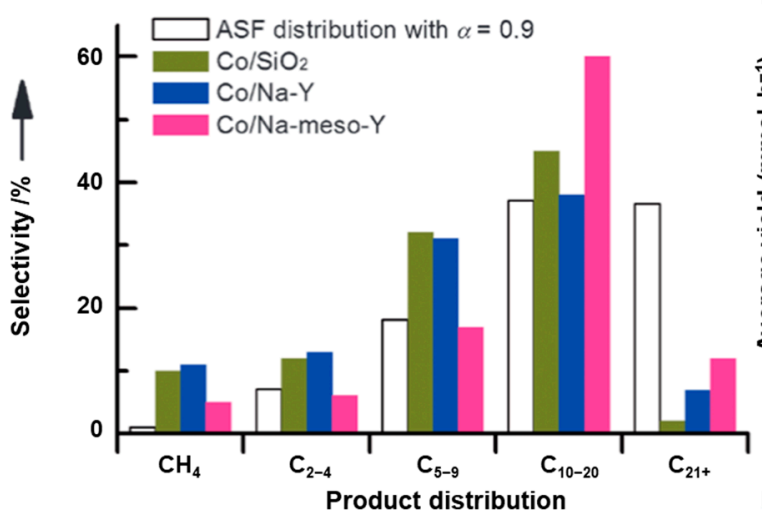

(b)
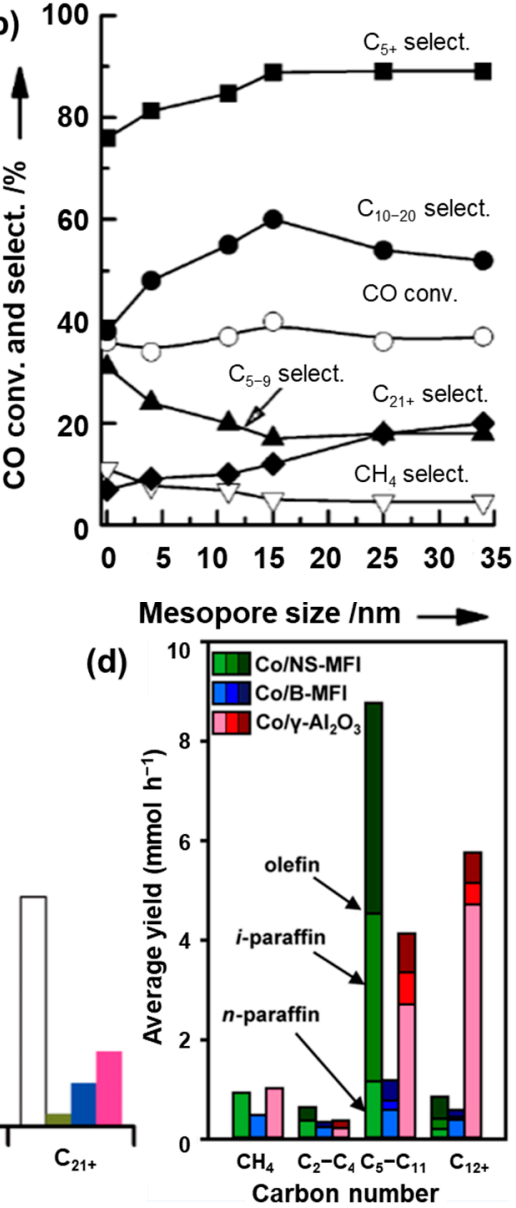

Figure 14. Fischer-Tropsch synthesis (FTS) for diesel fuel production over different catalysts. (a) Correlation between impregnated Co particle size and conversion/selectivity (\%) over $\mathrm{Co} / \mathrm{Na}-$ meso-Y catalysts; (b) the effect of mesopore size of the Co/Na-meso-Y catalysts; (c) product selectivity over $\mathrm{Co} / \mathrm{SiO}_{2}, \mathrm{Co} / \mathrm{Na}-\mathrm{Y}$, and $\mathrm{Co} / \mathrm{Na}$-meso-Y catalysts (selectivity from Anderson-Schulz-Flory (ASF) 
distribution ( $\alpha=0.9$ ) is also given). Reaction conditions: catalyst (Co loading, $15 \mathrm{wt} \%$ ) $0.5 \mathrm{~g}$, $503 \mathrm{~K}$, 2.0 Mpa, $\mathrm{H}_{2} / \mathrm{CO} 1: 1,20 \mathrm{~mL} \mathrm{~min}^{-1}$, and the time on stream = $12 \mathrm{~h}$ (adapted from reference [142]); (d) the product selectivity of Co/NS-MFI (NS: nanosponge mesoporous), Co/B-MFI (B: bulk microporous), and $\mathrm{Co} / \gamma-\mathrm{Al}_{2} \mathrm{O}_{3}$ catalysts. Reaction conditions: catalyst (Co loading $\left.=10 \mathrm{wt} \%\right) 0.5 \mathrm{~g}$ to $1.5 \mathrm{~g}$, $493 \mathrm{~K}, 2.0 \mathrm{MPa}, \mathrm{H}_{2} / \mathrm{CO}$ 2:1, $20 \mathrm{~mL} \mathrm{~min}^{-1}$, and $100 \mathrm{~h}$ time on stream (adapted from reference [145]).

\subsection{Fine-Chemical Syntheses}

In the past few years, researchers have widely investigated the role of zeolites as heterogeneous catalysts for the synthesis of chemical intermediates and fine chemicals. The variety of acid sites, pore architecture, structure stability, and morphologies in zeolites enable their use as heterogeneous catalysts for the synthesis of fine chemicals. In this section, we discuss the application of mesoporous zeolites in synthesis of fine chemicals, such as glycerol derived from biomass, and the cycloaddition of $\mathrm{CO}_{2}$ with epoxides.

\subsubsection{Conversion of Glycerol}

The conversion of glycerol to valuable chemicals has attracted growing interest owing to its large-scale co-production as a byproduct of biodiesel production $(\sim 10 \%$, which is expected to reach a global production of 6 million tons by 2025) [146-153]. Several reactions (hydrogenolysis, dehydration, dehydrogenation, oxidation, and esterification) with different catalysts have been performed to transform glycerol to value-added chemicals $[154,155]$. Mesoporous zeolites have demonstrated remarkable catalytic activity for the conversion of glycerol to various products compared with their microporous counterparts. Beerthuis et al. reported a facile synthesis of hierarchical (mesoporous) ZSM-5 and its application for conversion (dehydration) of glycerol to acrolein [156]. The study also compared the catalytic behavior of microporous ZSM- 5 (conventional) under similar reaction conditions. The synthesized hierarchical ZSM- 5 zeolites enhanced the dehydration of glycerol to acrolein and exhibited a five-fold improved catalytic stability, which were observed to be highly stable up to 10-24 h, compared to the conventional ZSM-5 ( 2-3 h). The improved catalytic stability was ascribed to the presence of tri-modal ZSM-5 structure (micro-, meso-, and macropores), which in turn reduced the coke formation. Possato et al. carried out a comparative study for glycerol dehydration to acrolein using micro- and mesoporous MFI zeolites [157]. The mesoporous MFI materials were obtained via alkalineassisted desilication of parent MFI. The authors presented in detail the catalytic behavior of MFI zeolites including the effect of desilication and porous structure (mono- and bimodal pores) on the deactivation of the catalysts. The catalytic performance of the parent MFI decreased constantly due to the coke formation in the straight and sinusoidal micropores, which in turn reduced the access of glycerol to active sites located in the channels of bulk microporous catalysts. In contrast, in hierarchical mesoporous MFI, the coke was mainly deposited in the intracrystalline pockets (created by the desilication), which resulted in stable MFI catalysts and enhanced catalytic performance. The authors further proposed that acidity and porosity are the key properties determining the overall catalytic activity of MFI zeolites.

Arellano et al. studied the effect of porosity and Si / Al ratio of MFI (ZSM-5) zeolites in etherification of glycerol with benzyl alcohol to form three different ethers (3-benzyloxy-1,2propanediol, 1,3-dibenzyloxy-2-propanol, and dibenzyl ether) [158]. Glycerol etherification with benzyl alcohol was performed over two microporous (Z15c; Si / Al = 19.5 and Z40c; $\mathrm{Si} / \mathrm{Al}=48.2)$ and a hierarchical $(\mathrm{Z} 40 \mathrm{c}-\mathrm{H} ; \mathrm{Si} / \mathrm{Al}=50.0)$ MFI zeolites. Mesoporous ZSM$5(\mathrm{Z} 40 \mathrm{c}-\mathrm{H})$ was obtained via the desilication of the microporous Z40c (alkali treatment) followed by $\mathrm{HCl}$ washing. The authors observed that both conventional and mesoporous ZSM-5 demonstrated similar catalytic activity. However, there was a major difference in the product selectivity; the bulky molecule product selectivity was significantly enhanced in mesoporous ZSM-5 (Z40c-H) than in the conventional ZSM-5 (Z15c and Z40c) zeolites. Xiao et al. reported the catalytic performance of mesoporous HZSM- 5 in the aromatization of glycerol and methanol into high-value aromatic BTX (benzene, toluene, and xylene) 
chemicals [159]. The authors synthesized various mesoporous MFI (HZSM-5) zeolites via alkaline-assisted desilication at different $\mathrm{NaOH}$ concentrations. Hierarchical HZSM-5 with the mesopore size of $\sim 4 \mathrm{~nm}$ showed an excellent catalytic lifetime and selectivity toward BTX products. The improved catalytic efficiency for mesoporous HZSM- 5 was attributed to the presence of bimodal micro-mesoporous HZSM- 5 structure (obtained by alkali-treated desilication), which reduced the diffusion path length and sustained the enough crystalline microporous frameworks.

\subsubsection{Cycloaddition of $\mathrm{CO}_{2}$ with Epoxides}

Incessant $\mathrm{CO}_{2}$ emission from fossil-based fuel/chemical industries is one of the biggest concerns to society [160-162]. Several materials (e.g., metal-organic frameworks, mesoporous silica, zeolites, and metal oxides) have been utilized for $\mathrm{CO}_{2}$ consumption and its conversion to various chemicals. The cycloaddition of $\mathrm{CO}_{2}$ with epoxides is a vital reaction for synthesis of cyclic carbonates, which are widely used in pharmaceuticals, polymer industry, and biomedical applications $[163,164]$. Li et al. reported the synthesis of cyclic carbonates from the cycloaddition of $\mathrm{CO}_{2}$ with various epoxides over novel organic-inorganic hybrid mesoporous lamellar MFI zeolite (Figure 15) [165]. The lamellar MFI zeolite was synthesized via soft-templating route using an amphiphilic SDA; $\left.\mathrm{C}_{18} \mathrm{H}_{37} \mathrm{Me}_{2} \mathrm{~N}^{+}\left(\mathrm{CH}_{2}\right)_{6} \mathrm{~N}^{+} \mathrm{Pr}_{3}\right] \mathrm{Br}_{2}$ (abbreviated as $\left.\mathrm{C}_{18-6-3}\right)$. The synthesized lamellar MFI (LMFI-AS) and iodide ion-exchanged (LMFI-I) zeolites served as potential catalysts for synthesis of a various cyclic carbonates from their corresponding epoxides. In particular, LMFI-I catalyst demonstrated an excellent catalytic performance with good recyclability. The superior catalytic performance of LMFI-I catalyst was attributed to a larger anion radius, which weakened the interaction between the nucleus and the valence electron. Therefore, $\mathrm{I}^{-}$(from LMFI-I) preferred to attack on the $\alpha-\mathrm{C}$ of epoxides. During the solventfree cycloaddition reaction, the quaternary ammonium cations (present in SDA) and the iodide ions worked synergistically, thereby selectively producing carbonates with good catalytic stability and reusability. In another study, Kim et al. investigated the synthesis of organic-inorganic hybrid mesoporous $\mathrm{BEA}$ zeolite by tethering the $\mathrm{NH}_{3} \mathrm{Br}$ on the mesopore walls through $\mathrm{Si}-\mathrm{O}-\mathrm{Si}$ linkages. The synthesized mesoporous BEA catalysts were applied in the cycloaddition of $\mathrm{CO}_{2}$ with propylene oxide (PO) to synthesize propylene carbonate (PC) [166]. Mesoporous BEA zeolites exhibited better catalytic performance than did the catalysts with single functionalities, such as the acidic BEA zeolite without the $\mathrm{NH}_{3} \mathrm{Br}$ group. The authors determined that the increased proximity between BEA zeolite acid sites and $\mathrm{NH}_{3} \mathrm{Br}$ decreased the activation energy, which eventually enhanced the catalytic reaction rate compared with the $\mathrm{NH}_{3} \mathrm{Br} / \mathrm{Al}-\mathrm{SBA}-15$ catalyst. The study further revealed that the mesoporous BEA-based hybrid material was found to be a more stable heterogeneous catalyst, which exhibited high catalytic performance and good recyclability (up to five runs) in the organic solvent-free reaction.

\subsection{Dehydrogenation of Light Alkanes}

Dehydrogenation of light alkanes to produce light olefins, which is very useful in the chemical industry, has been attracting a lot of attention due to the sudden increase in light alkanes supply from the shale gas revolution [167]. The reaction is highly endothermic, which implies that higher reaction temperature is needed to achieve high conversion (typically $550-750^{\circ} \mathrm{C}$ ). For example, conventional dehydrogenation process is conducted using PtSn bimetallic catalysts supported on porous alumina. Although the Pt metal itself shows very high initial activity, it is rapidly deactivated by coke deposition. To alleviate these problems, inactive $\mathrm{Sn}$ is added to form an alloy with $\mathrm{Pt}$ and dilutes its active surface, and the coke deposition is thereby reduced. Good supports for dehydrogenation of alkanes have to be thermally stable under the harsh conditions and have limited acidity to avoid undesirable side reactions, such as alkane isomerization and coke formation, and zeolites are commonly used alternative supports for dehydrogenation catalysts. 

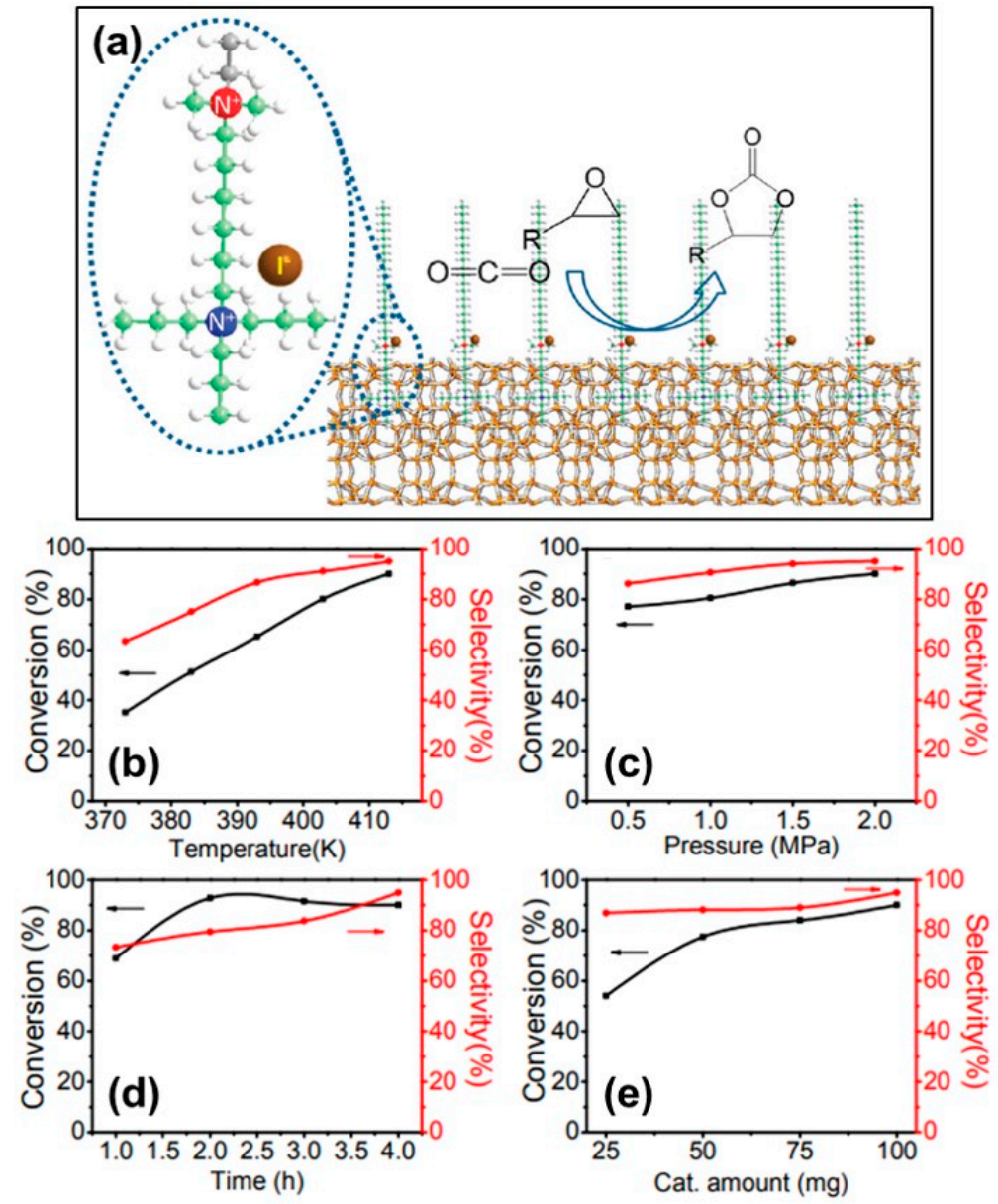

Figure 15. (a) Schematic diagram for the cycloaddition of epoxides and $\mathrm{CO}_{2}$ over iodide (anion)exchanged organic-inorganic hybrid mesoporous MFI catalyst (LMFI-I); (b-e) the effect of reaction temperature (b), $\mathrm{CO}_{2}$ pressure $(\mathbf{c})$, reaction time $(\mathbf{d})$, and amount of the catalyst $(\mathbf{e})$ on the conversion and selectivity of corresponding products from cycloaddition of $\mathrm{CO}_{2}$ and epoxides over LMFI-I zeolite catalyst. Reaction conditions: $413 \mathrm{~K}, 2.0 \mathrm{MPa} \mathrm{CO}_{2}$ pressure, $4 \mathrm{~h}$ reaction time, $100 \mathrm{mg}$ LMFI-I catalyst, and $10 \mathrm{mmol}$ epichlorohydrin (adapted from reference [165]).

Ryoo's group recently enables alloy formations between rare-earth element (REE) oxides and $\mathrm{Pt}$, which is almost impossible due to its low chemical potential, through surface framework defects (called 'silanol nests') on the mesoporous zeolite [168]. They found that silanol nests allow REE to exist as single atomic species with much higher chemical potential compared with that of the bulk oxide, making them diffuse onto Pt. Catalytic performance of Pt-REE intermetallic nanoparticles supported on the mesoporous zeolite in propane dehydrogenation (PDH) exhibited a striking enhancement in all aspects of the catalytic performance, including activity, selectivity, and durability. Compared to conventional PtSn/alumina catalyst showing severe coke formation and catalytic deactivation ( $36 \%$ to $\sim 5 \%$ ) within 1 day, $\mathrm{Pt}_{3} \mathrm{La}$ intermetallic nanoparticles supported on the degallated zeolite (PtLa/mz-deGa) showed an initial propane conversion of $40 \%$ (close to the equilibrium conversion) and underwent extremely slow deactivation, retaining $8 \%$ conversion even after 30 days of reaction. The same group used the mesoporous zeolite as a support that enables the formation of finely dispersed $\mathrm{Pt}_{1} \mathrm{Zn}_{1}$ intermetallic compound-type alloy nanoparticles [169]. This catalyst showed highly active and selective in the PDH and exhibited outstanding catalytic durability, which was the highest among those of the reported Pt-based alloy catalyst. 


\section{Conclusions and Perspectives}

Mesoporous zeolites are considered as attractive heterogeneous catalysts for use in several significant reactions (especially involving bulky molecules) to produce various value-added chemicals and have demonstrated a clear advantage over their conventional zeolite counterparts. Over the past few decades, various strategies have been developed for the synthesis of mesoporous zeolites. In this review, we have highlighted some of the key approaches, including templating (hard and soft templating) and post-synthesis treatment/demetallation (dealumination and desilication) methods. The templating approach is known to be a facile approach for controlled mesoporous structure generation. However, both hard and soft-templating methods need further improvements from the commercial and environmental standpoints. Hard templates are expensive and non-recyclable and hence not applicable on an industrial scale. The cationic amphiphilic template (applicable in soft templating) itself requires multistep organic synthesis route, which makes it cost sensitive, time consuming, detrimental to the environment, and eventually limits its industrial scope. The creation of mesoporous zeolitic structures via post-synthesis methods (demetallation: dealumination and desilication) has an advantage over the templating approach as it does not require any templates; therefore, it has been applied in various industrial applications. However, in dealumination, the number of acid sites decreases due to the extraction of $\mathrm{Al}$ from the framework. Moreover, $\mathrm{EF}_{\mathrm{Al}}$ can be generated by shifting the $\mathrm{F}_{\mathrm{Al}}$ to the extra-framework octahedral $\mathrm{Al}$ arrangement, which has been considered as unfriendly to some of the reactions because $\mathrm{EF}_{\mathrm{Al}}$ promotes faster catalyst deactivation and coke formation. For desilication, in contrast, substantial loss of microporous structure and materials in desilication route are the biggest concerns for its large-scale applications. Therefore, for the synthesis of mesoporous zeolites, it is imperative to design strategies that are facile, economical, ecofriendly, and scalable.

A broader study on the catalytic behavior of a series of mesoporous zeolites at various reaction conditions is necessary for better understanding the reaction mechanisms and correlations between the different zeolite structures and their catalytic performance for a given set of reactions (the determination of structure-activity relationship; activity and shape selectivity toward the desired product). For making deeper insight on the nature of active sites during catalysis, studies on the applications of mesoporous zeolites in heterogeneous catalysis should be focused on operando and in situ spectroscopic characterizations. Furthermore, the extension of mesoporous zeolites to applications beyond the petrochemical industry, such as sensors, energy materials, and in healthcare products, can propel zeolites to the forefront of heterogeneous catalysis applications used in modern technology.

Author Contributions: K.N. designed the whole contents of the manuscript. B.K.S., Y.K., S.K. and K.N. wrote and polished the manuscript together. All authors have read and agreed to the published version of the manuscript.

Funding: This work was supported by a National Research Foundation of Korea (NRF) grant, funded by the Korean Government (MSIT) (NRF-2021R1A2C2008362). This study was financially supported by Chonnam National University (Grant number: 2020-3879).

Conflicts of Interest: The authors declare no conflict of interest.

\section{References}

1. Li, R.; Xue, T.; Bingre, R.; Gao, Y.; Louis, B.; Wang, Q. Microporous Zeolite@Vertically Aligned Mg-Al Layered Double Hydroxide Core@Shell Structures with Improved Hydrophobicity and Toluene Adsorption Capacity under Wet Conditions. ACS Appl. Mater. Interfaces 2018, 10, 34834-34839. [CrossRef]

2. Park, B.-G.; Chung, K.-H. Catalytic properties of microporous zeolites in the catalytic cracking of $m$-diisopropylbenzene. Mol. Catal. 2018, 461, 80-85. [CrossRef]

3. Awala, H.; Gilson, J.-P.; Retoux, R.; Boullay, P.; Goupil, J.-M.; Valtchev, V.; Mintova, S. Template-free nanosized faujasite-type zeolites. Nat. Mater. 2015, 14, 447-451. [CrossRef] [PubMed]

4. Usman, M.; Zhu, J.; Chuiyang, K.; Arslan, M.T.; Khan, A.; Galadima, A.; Muraza, O.; Khan, I.; Helal, A.; Al-Maythalony, B.A.; et al. Propene Adsorption-Chemisorption Behaviors on H-SAPO-34 Zeolite Catalysts at Different Temperatures. Catalysts 2019, 9, 919. [CrossRef] 
5. Zhang, N.; Xin, Y.; Li, Q.; Ma, X.; Qi, Y.; Zheng, L.; Zhang, Z. Ion Exchange of One-Pot Synthesized Cu-SAPO-44 with NH $\mathrm{NO}_{3}$ to Promote $\mathrm{Cu}$ Dispersion and Activity for Selective Catalytic Reduction of $\mathrm{NO}_{x}$ with $\mathrm{NH}_{3}$. Catalysts 2019, 9, 882. [CrossRef]

6. Bhadauria, J.; Singh, B.K.; Tomar, A.; Tomar, R. Synthesis and characterization of analogue of mordenite and its role as a catalyst for Friedel-Crafts acylation of anisole. J. Chem. Pharm. Res. 2011, 3, 245-257.

7. Singh, B.K.; Lee, S.; Na, K. An overview on metal-related catalysts: Metal oxides, nanoporous metals and supported metal nanoparticles on metal organic frameworks and zeolites. Rare Metals 2020, 39, 751-766. [CrossRef]

8. Kwon, S.; Choi, Y.; Singh, B.K.; Na, K. Selective and rapid capture of Sr ${ }^{2+}$ with LTA zeolites: Effect of crystal sizes and mesoporosity. Appl. Surf. Sci. 2020, 506, 145029. [CrossRef]

9. Millini, R.; Bellussi, G.; Smeets, S.; Xiaodong, Z.; Strohmaier, K. Zeolites in Catalysis: Properties and Applications. R. Soc. Chem. 2017, 28, 4. [CrossRef]

10. Baerlocher, C.; McCusker, L.B.; Structure Commission of the International Zeolite Association (IZA-SC). Database of Zeolite Structures. 2013. Available online: http:/ / www.iza-online.org/ (accessed on 15 November 2021).

11. Na, K.; Somorjai, G.A. Hierarchically nanoporous zeolites and their heterogeneous catalysis: Current status and future perspectives. Catal. Lett. 2015, 145, 193-213. [CrossRef]

12. Bereciartua, P.J.; Cantín, Á.; Corma, A.; Jordá, J.L.; Palomino, M.; Rey, F.; Valencia, S.; Corcoran, E.W.; Kortunov, P.; Ravikovitch, P.I.; et al. Control of zeolite framework flexibility and pore topology for separation of ethane and ethylene. Science 2017, 358, 1068-1071. [CrossRef]

13. Pan, T.; Wu, Z.; Yip, A.C.K. Advances in the Green Synthesis of Microporous and Hierarchical Zeolites: A Short Review. Catalysts 2019, 9, 274. [CrossRef]

14. Abdulridha, S.; Jiao, Y.; Xu, S.; Zhang, R.; Ren, Z.; Garforth, A.A.; Fan, X. A Comparative Study on Mesoporous Y Zeolites Prepared by Hard-Templating and Post-Synthetic Treatment Methods. Appl. Catal. A Gen. 2021, 612, 117986. [CrossRef]

15. Losch, P.; Hoff, T.C.; Kolb, J.F.; Bernardon, C.; Tessonnier, J.-P.; Louis, B. Mesoporous ZSM-5 zeolites in acid catalysis: Top-down vs. Bottom-up approach. Catalysts 2017, 7, 225. [CrossRef]

16. Meng, X.; Nawaz, F.; Xiao, F.-S. Templating route for synthesizing mesoporous zeolites with improved catalytic properties. Nano Today 2009, 4, 292-301. [CrossRef]

17. Szczęśniak, B.; Choma, J.; Jaroniec, M. Major advances in the development of ordered mesoporous materials. Chem. Commun. 2020, 56, 7836-7848. [CrossRef]

18. Wan, Y.; Zhao, D. On the controllable soft-templating approach to mesoporous silicates. Chem. Rev. 2007, 107, 2821-2860. [CrossRef]

19. Wei, Y.; Parmentier, T.E.; de Jong, K.P.; Zečević, J. Tailoring and visualizing the pore architecture of hierarchical zeolites. Chem. Soc. Rev. 2015, 44, 7234-7261. [CrossRef]

20. Xu, D.; Jing, Z.; Cao, F.; Sun, H.; Che, S. Surfactants with aromatic-group tail and single quaternary ammonium head for directing single-crystalline mesostructured zeolite nanosheets. Chem. Mater. 2014, 26, 4612-4619. [CrossRef]

21. Jia, X.; Jo, C.; Yip, A.C. Synthesis Strategies for Hierarchical Zeolites. Heterogeneous Catalysts: Advanced Design. Charact. Appl. 2021, 1, 119-145.

22. Jiao, Y.; Forster, L.; Xu, S.; Chen, H.; Han, J.; Liu, X.; Zhou, Y.; Liu, J.; Zhang, J.; Yu, J.; et al. Creation of Al-Enriched Mesoporous ZSM-5 Nanoboxes with High Catalytic Activity: Converting Tetrahedral Extra-Framework Al into Framework Sites by Post Treatment. Angew. Chem. Int. Ed. 2020, 59, 19478-19486. [CrossRef] [PubMed]

23. Pyra, K.; Tarach, K.A.; Góra-Marek, K. Towards a greater olefin share in polypropylene cracking-Amorphous mesoporous aluminosilicate competes with zeolites. Appl. Catal. B 2021, 297, 120408. [CrossRef]

24. Sun, M.H.; Chen, L.H.; Yu, S.; Li, Y.; Zhou, X.G.; Hu, Z.Y.; Sun, Y.H.; Xu, Y.; Su, B.L. Micron-Sized Zeolite Beta Single Crystals Featuring Intracrystal Interconnected Ordered Macro-Meso-Microporosity Displaying Superior Catalytic Performance. Angew. Chem. Int. Ed. 2020, 59, 19582-19591. [CrossRef]

25. Meng, Q.; Doetschman, D.C.; Rizos, A.K.; Lee, M.H.; Schulte, J.T.; Spyros, A.; Kanyi, C.W. Adsorption of organophosphates into microporous and mesoporous $\mathrm{NaX}$ zeolites and subsequent chemistry. Environ. Sci. Technol. 2011, 45, 3000-3005. [CrossRef]

26. Fattahi, N.; Triantafyllidis, K.; Luque, R.; Ramazani, A. Zeolite-Based Catalysts: A Valuable Approach toward Ester Bond Formation. Catalysts 2019, 9, 758. [CrossRef]

27. Möller, K.; Bein, T. Mesoporosity-A new dimension for zeolites. Chem. Soc. Rev. 2013, 42, 3689-3707. [CrossRef]

28. Madsen, C.; Jacobsen, C.H. Nanosized zeolite crystals-Convenient control of crystal size distribution by confined space synthesis. Chem. Commun. 1999, 8, 673-674. [CrossRef]

29. Jacobsen, C.J.; Madsen, C.; Houzvicka, J.; Schmidt, I.; Carlsson, A. Mesoporous zeolite single crystals. J. Am. Chem. Soc. 2000, 122, 7116-7117. [CrossRef]

30. Schmidt, I.; Boisen, A.; Gustavsson, E.; Ståhl, K.; Pehrson, S.; Dahl, S.; Carlsson, A.; Jacobsen, C.J. Carbon nanotube templated growth of mesoporous zeolite single crystals. Chem. Mater. 2001, 13, 4416-4418. [CrossRef]

31. Schmidt, F.; Paasch, S.; Brunner, E.; Kaskel, S. Carbon templated SAPO-34 with improved adsorption kinetics and catalytic performance in the MTO-reaction. Microporous Mesoporous Mater. 2012, 164, 214-221. [CrossRef]

32. Yang, Z.X.; Xia, Y.D.; Mokaya, R. Zeolite ZSM-5 with unique supermicropores synthesized using mesoporous carbon as a template. Adv. Mater. 2004, 16, 727-732. [CrossRef]

33. Tao, Y.; Kanoh, H.; Kaneko, K. ZSM-5 monolith of uniform mesoporous channels. J. Am. Chem. Soc. 2003, 125, 6044-6045. [CrossRef] 
34. Tao, Y.; Kanoh, H.; Kaneko, K. Uniform mesopore-donated zeolite Y using carbon aerogel templating. J. Phys. Chem. B 2003, 107, 10974-10976. [CrossRef]

35. White, R.J.; Fischer, A.; Goebel, C.; Thomas, A. A sustainable template for mesoporous zeolite synthesis. J. Am. Chem. Soc. 2014, 136, 2715-2718. [CrossRef]

36. Abdulridha, S.; Jiang, J.; Xu, S.; Zhou, Z.; Liang, H.; Mao, B.; Zhou, Y.; Garforth, A.A.; Jiao, Y.; Fan, X. Cellulose nanocrystals (CNCs) as hard templates for preparing mesoporous zeolite $\mathrm{Y}$ assemblies with high catalytic activity. Green Chem. 2020, 22, 5115-5122. [CrossRef]

37. Wei, X.; Smirniotis, P.G. Synthesis and characterization of mesoporous ZSM-12 by using carbon particles. Microporous Mesoporous Mater. 2006, 89, 170-178. [CrossRef]

38. Sakthivel, A.; Huang, S.J.; Chen, W.H.; Lan, Z.H.; Chen, K.H.; Kim, T.W.; Ryoo, R.; Chiang, A.S.; Liu, S.B. Replication of mesoporous aluminosilicate molecular sieves (RMMs) with zeolite framework from mesoporous carbons (CMKs). Chem. Mater. 2004, 16, 3168-3175. [CrossRef]

39. Fang, Y.; Hu, H. An ordered mesoporous aluminosilicate with completely crystalline zeolite wall structure. J. Am. Chem. Soc. 2006, 128, 10636-10637. [CrossRef]

40. Fan, W.; Snyder, M.A.; Kumar, S.; Lee, P.S.; Yoo, W.C.; McCormick, A.V.; Penn, R.L.; Stein, A.; Tsapatsis, M. Hierarchical nanofabrication of microporous crystals with ordered mesoporosity. Nat. Mater. 2008, 7, 984. [CrossRef]

41. Chen, H.; Wydra, J.; Zhang, X.; Lee, P.S.; Wang, Z.; Fan, W.; Tsapatsis, M. Hydrothermal synthesis of zeolites with threedimensionally ordered mesoporous-imprinted structure. J. Am. Chem. Soc. 2011, 133, 12390-12393. [CrossRef] [PubMed]

42. Zhou, J.; Hua, Z.; Liu, Z.; Wu, W.; Zhu, Y.; Shi, J. Direct synthetic strategy of mesoporous ZSM-5 zeolites by using conventional block copolymer templates and the improved catalytic properties. ACS Catal. 2011, 1, 287-291. [CrossRef]

43. Shen, X.; Mao, W.; Ma, Y.; Xu, D.; Wu, P.; Terasaki, O.; Han, L.; Che, S. A hierarchical MFI zeolite with a two-dimensional square mesostructure. Angew. Chem. Int. Ed. 2018, 57, 724-728. [CrossRef] [PubMed]

44. Zhang, Y.; Shen, X.; Gong, Z.; Han, L.; Sun, H.; Che, S. Single-Crystalline MFI Zeolite with Sheet-Like Mesopores Layered along the a-Axis. Chem. Eur. J. 2019, 25, 738-742. [CrossRef]

45. Xiao, F.S.; Wang, L.; Yin, C.; Lin, K.; Di, Y.; Li, J.; Xu, R.; Su, D.S.; Schlögl, R.; Yokoi, T.; et al. Catalytic properties of hierarchical mesoporous zeolites templated with a mixture of small organic ammonium salts and mesoscale cationic polymers. Angew. Chem. Int. Ed. 2006, 45, 3090-3093. [CrossRef]

46. Na, K.; Park, W.; Seo, Y.; Ryoo, R. Disordered assembly of MFI zeolite nanosheets with a large volume of intersheet mesopores. Chem. Mat. 2011, 23, 1273-1279. [CrossRef]

47. Choi, M.; Na, K.; Kim, J.; Sakamoto, Y.; Terasaki, O.; Ryoo, R. Stable single-unit-cell nanosheets of zeolite MFI as active and long-lived catalysts. Nature 2009, 461, 246-249. [CrossRef]

48. Na, K.; Choi, M.; Park, W.; Sakamoto, Y.; Terasaki, O.; Ryoo, R. Pillared MFI zeolite nanosheets of a single-unit-cell thickness. J. Am. Chem. Soc. 2010, 132, 4169-4177. [CrossRef]

49. Na, K.; Jo, C.; Kim, J.; Cho, K.; Jung, J.; Seo, Y.; Messinger, R.J.; Chmelka, B.F.; Ryoo, R. Directing zeolite structures into hierarchically nanoporous architectures. Science 2011, 333, 328-332. [CrossRef]

50. Xu, D.; Ma, Y.; Jing, Z.; Han, L.; Singh, B.; Feng, J.; Shen, X.; Cao, F.; Oleynikov, P.; Sun, H.; et al. $\pi-\pi$ interaction of aromatic groups in amphiphilic molecules directing for single-crystalline mesostructured zeolite nanosheets. Nat. Commun. 2014, 5, 4262. [CrossRef]

51. Singh, B.K.; Xu, D.; Han, L.; Ding, J.; Wang, Y.; Che, S. Synthesis of single-crystalline mesoporous ZSM-5 with three-dimensional pores via the self-assembly of a designed triply branched cationic surfactant. Chem. Mater. 2014, 26, 7183-7188. [CrossRef]

52. Choi, M.; Na, K.; Ryoo, R. The synthesis of a hierarchically porous BEA zeolite via pseudomorphic crystallization. Chem. Commun. 2009, 20, 2845-2847. [CrossRef]

53. Na, K.; Choi, M.; Ryoo, R. Cyclic diquaternary ammoniums for nanocrystalline BEA, MTW and MFI zeolites with intercrystalline mesoporosity. J. Mater. Chem. 2009, 19, 6713-6719. [CrossRef]

54. Schwieger, W.; Machoke, A.G.; Weissenberger, T.; Inayat, A.; Selvam, T.; Klumpp, M.; Inayat, A. Hierarchy concepts: Classification and preparation strategies for zeolite containing materials with hierarchical porosity. Chem. Soc. Rev. 2016, 45, 3353-3376. [CrossRef] [PubMed]

55. Chen, C.; Hu, Z.; Ren, J.; Zhang, S.; Wang, Z.; Yuan, Z.-Y. ZnO Nanoclusters Supported on Dealuminated Zeolite $\beta$ as a Novel Catalyst for Direct Dehyrdogenation of Propane to Propylene. ChemCatChem 2019, 11, 868-877. [CrossRef]

56. Guisnet, M.; Ribeiro, F.R. Deactivation and Regeneration of Solid Catalysts; Imperial College Press: London, UK, 2011; pp. 3-18. [CrossRef]

57. Zukal, A.; Patzelová, V.; Lohse, U. Secondary porous structure of dealuminated Y zeolites. Zeolites 1986, 6, 133-136. [CrossRef]

58. Chal, R.; Gérardin, C.; Bulut, M.; van Donk, S. Overview and industrial assessment of synthesis strategies towards zeolites with mesopores. ChemCatChem 2011, 3, 67-81. [CrossRef]

59. Feliczak-Guzik, A. Hierarchical zeolites: Synthesis and catalytic properties. Microporous Mesoporous Mater. 2018, 259, 33-45. [CrossRef]

60. van Oers, C.J.; Stevens, W.J.J.; Bruijn, E.; Mertens, M.; Lebedev, O.I.; van Tendeloo, G.; Meynen, V.; Cool, P. Formation of a combined micro-and mesoporous material using zeolite Beta nanoparticles. Microporous Mesoporous Mater. 2009, 120, 29-34. [CrossRef]

61. Sulikowski, B. The fractal dimension in molecular sieves: Synthetic faujasite and related solids. J. Phys. Chem. B 1993, 97, 1420-1425. [CrossRef] 
62. González, M.D.; Cesteros, Y.; Salagre, P. Comparison of dealumination of zeolites beta, mordenite and ZSM-5 by treatment with acid under microwave irradiation. Microporous Mesoporous Mater. 2011, 144, 162-170. [CrossRef]

63. Groen, J.C.; Zhu, W.; Brouwer, S.; Huynink, S.J.; Kapteijn, F.; Moulijn, J.A.; Pérez-Ramírez, J. Direct demonstration of enhanced diffusion in mesoporous ZSM-5 zeolite obtained via controlled desilication. J. Am. Chem. Soc. 2007, 129, 355-360. [CrossRef]

64. Ogura, M.; Shinomiya, S.-Y.; Tateno, J.; Nara, Y.; Nomura, M.; Kikuchi, E.; Matsukata, M. Alkali-treatment technique-new method for modification of structural and acid-catalytic properties of ZSM-5 zeolites. Appl. Catal. A Gen. 2001, 219, 33-43. [CrossRef]

65. Groen, J.C.; Jansen, J.C.; Moulijn, J.A.; Pérez-Ramírez, J. Optimal aluminum-assisted mesoporosity development in MFI zeolites by desilication. J. Phys. Chem. B 2004, 108, 13062-13065. [CrossRef]

66. Verboekend, D.; Pérez-Ramírez, J. Desilication mechanism revisited: Highly mesoporous all-silica zeolites enabled through pore-directing agents. Chem. Eur. J. 2011, 17, 1137-1147. [CrossRef]

67. Abelló, S.; Bonilla, A.; Pérez-Ramírez, J. Mesoporous ZSM-5 zeolite catalysts prepared by desilication with organic hydroxides and comparison with $\mathrm{NaOH}$ leaching. Appl. Catal. A Gen. 2009, 364, 191-198. [CrossRef]

68. Pérez-Ramírez, J.; Verboekend, D.; Bonilla, A.; Abelló, S. Zeolite catalysts with tunable hierarchy factor by pore-growth moderators Adv. Funct. Mat. 2009, 19, 3972-3979. [CrossRef]

69. Wojciechowski, B.W.; Corma, A. Catalytic Cracking: Catalysts, Chemistry, and Kinetics; Marcel Dekker Inc.: New York, NY, USA, 1986.

70. Li, K.; Valla, J.; Garcia-Martinez, J. Realizing the commercial potential of hierarchical zeolites: New opportunities in catalytic cracking. ChemCatChem 2014, 6, 46-66. [CrossRef]

71. van Donk, S.; Janssen, A.H.; Bitter, J.H.; de Jong, K.P. Generation, characterization, and impact of mesopores in zeolite catalysts. Catal. Rev. 2003, 45, 297-319. [CrossRef]

72. Vogt, E.T.C.; Weckhuysen, B.M. Fluid catalytic cracking: Recent developments on the grand old lady of zeolite catalysis. Chem. Soc. Rev. 2015, 44, 7342-7370. [CrossRef] [PubMed]

73. Jung, J.S.; Park, J.W.; Seo, G. Catalytic cracking of n-octane over alkali-treated MFI zeolites. Appl. Catal. A Gen. 2005, 288, 149-157. [CrossRef]

74. Rahimi, N.; Karimzadeh, R. Catalytic cracking of hydrocarbons over modified ZSM-5 zeolites to produce light olefins: A review. Appl. Catal. A Gen. 2011, 398,1-17. [CrossRef]

75. Suzuki, K.; Aoyagi, Y.; Katada, N.; Choi, M.; Ryoo, R.; Niwa, M. Acidity and catalytic activity of mesoporous ZSM-5 in comparison with zeolite ZSM-5, Al-MCM-41 and silica-alumina. Catal. Today 2008, 132, 38-45. [CrossRef]

76. Li, Y.; Liu, S.; Zhang, Z.; Xie, S.; Zhu, X.; Xu, L. Aromatization and isomerization of 1-hexene over alkali-treated HZSM-5 zeolites: Improved reaction stability. Appl. Catal. A Gen. 2008, 338, 100-113. [CrossRef]

77. Zheng, J.; Zhang, X.; Wang, Y.; Bai, Y.; Sun, W.; Li, R. Synthesis and catalytic performance of a bi-phase core-shell zeolite composite. J. Porous Mater. 2009, 16, 731. [CrossRef]

78. Christensen, C.H.; Schmidt, I.; Christensen, C.H. Improved performance of mesoporous zeolite single crystals in catalytic cracking and isomerization of n-hexadecane. Catal. Commun. 2004, 5, 543-546. [CrossRef]

79. Kustova, M.Y.; Hasselriis, P.; Christensen, C.H. Mesoporous MEL-type zeolite single crystal catalysts. Catal. Lett. 2004, 96, 205-211. [CrossRef]

80. Lei, Q.; Zhao, T.; Li, F.; Zhang, L.; Wang, Y. Catalytic cracking of large molecules over hierarchical zeolites. Chem. Commun. 2006, 16, 1769-1771. [CrossRef]

81. Zhu, H.; Liu, Z.; Kong, D.; Wang, Y.; Xie, Z. Synthesis and catalytic performances of mesoporous zeolites templated by polyvinyl butyral gel as the mesopore directing agent. J. Phys. Chem. C 2008, 112, 17257-17264. [CrossRef]

82. Saravanamurugan, S.; Paniagua, M.; Melero, J.A.; Riisager, A. Efficient isomerization of glucose to fructose over zeolites in consecutive reactions in alcohol and aqueous media. J. Am. Chem. Soc. 2013, 135, 5246-5249. [CrossRef]

83. De Ménorval, B.; Ayrault, P.; Gnep, N.S.; Guisnet, M. Mechanism of n-butene skeletal isomerization over HFER zeolites: A new proposal. J. Catal. 2005, 230, 38-51. [CrossRef]

84. Moushey, D.L.; Smirniotis, P.G. $n$-Heptane hydroisomerization over mesoporous zeolites made by utilizing carbon particles as the template for mesoporosity. Catal. Lett. 2009, 129, 20-25. [CrossRef]

85. Modhera, B.K.; Chakraborty, M.; Bajaj, H.C.; Parikh, P.A. Influences of mesoporosity generation in ZSM-5 and zeolite beta on catalytic performance during $n$-hexane isomerization. Catal. Lett. 2011, 141, 1182-1190. [CrossRef]

86. Fedyna, M.; Śliwa, M.; Jaroszewska, K.; Trawczyński, J. Effect of zeolite amount on the properties of Pt/(AlSBA-15 + Beta zeolite) micro-mesoporous catalysts for the hydroisomerization of $n$-heptane. Fuel 2020, 280, 118607. [CrossRef]

87. Verboekend, D.; Thomas, K.; Milina, M.; Mitchell, S.; Pérez-Ramírez, J.; Gilson, J.-P. Towards more efficient monodimensional zeolite catalysts: N-alkane hydro-isomerisation on hierarchical ZSM-22. Catal. Sci. Technol. 2011, 1, 1331-1335. [CrossRef]

88. Martens, J.A.; Verboekend, D.; Thomas, K.; Vanbutsele, G.; Gilson, J.-P.; Pérez-Ramírez, J. Hydroisomerization of emerging renewable hydrocarbons using hierarchical Pt/H-ZSM-22 catalyst. ChemSusChem 2013, 6, 421-425. [CrossRef]

89. Musselwhite, N.; Na, K.; Sabyrov, K.; Alayoglu, S.; Somorjai, G.A. Mesoporous Aluminosilicate Catalysts for the Selective Isomerization of $n$-Hexane: The Roles of Surface Acidity and Platinum Metal. J. Am. Chem. Soc. 2015, 137, 10231-10237. [CrossRef]

90. Qin, B.; Zhang, X.; Zhang, Z.; Ling, F.; Sun, W. Synthesis, characterization and catalytic properties of Y- $\beta$ zeolite composites. Pet. Sci. 2011, 8, 224-228. [CrossRef]

91. Pellet, R.J.; Casey, D.G.; Huang, H.M.; Kessler, R.V.; Kuhlman, E.J.; Oyoung, C.L.; Sawicki, R.A.; Ugolini, J.R. Isomerization of $n$-butene to isobutene by ferrierite and modified ferrierite catalysts. J. Catal. 1995, 157, 423-435. [CrossRef] 
92. Zhang, S.; Zhang, Z.C. Skeletal isomerization of unsaturated fatty acids: The role of mesopores in HBeta zeolites. Catal. Lett. 2007, 115, 114-121. [CrossRef]

93. Chica, A.; Diaz, U.; Fornés, V.; Corma, A. Changing the hydroisomerization to hydrocracking ratio of long chain alkanes by varying the level of delamination in zeolitic (ITQ-6) materials. Catal. Today 2009, 147, 179-185. [CrossRef]

94. Fernandez, C.; Stan, I.; Gilson, J.-P.; Thomas, K.; Vicente, A.; Bonilla, A.; Pérez-Ramírez, J. Hierarchical ZSM-5 zeolites in shape-selective xylene isomerization: Role of mesoporosity and acid site speciation. Chem. Eur. J. 2010, 16, 6224-6233. [CrossRef]

95. Mokrzycki, Ł.; Sulikowski, B. Desilication of ZSM-12 and MCM-22 type zeolites and their performance in isomerization of $\alpha$-pinene. Stud. Surf. Sci. Catal. 2008, 174, 1231-1234. [CrossRef]

96. Mokrzycki, Ł.; Sulikowski, B.; Olejniczak, Z. Properties of Desilicated ZSM-5, ZSM-12, MCM-22 and ZSM-12/MCM-41 Derivatives in Isomerization of $\alpha$-Pinene. Catal. Lett. 2009, 127, 296. [CrossRef]

97. Sartori, G.; Maggi, R. Use of solid catalysts in Friedel-Crafts acylation reactions. Chem. Rev. 2006, 106, 1077-1104. [CrossRef]

98. Bejblová, M.; Procházková, D.; Čejka, J. Acylation reactions over zeolites and mesoporous catalysts. ChemSusChem 2009, 2, 486-499. [CrossRef] [PubMed]

99. Holm, M.S.; Taarning, E.; Egeblad, K.; Christensen, C.H. Catalysis with hierarchical zeolites. Catal. Today 2011, 168, 3-16. [CrossRef]

100. Christensen, C.H.; Johannsen, K.; Schmidt, I.; Christensen, C.H. Catalytic benzene alkylation over mesoporous zeolite single crystals: Improving activity and selectivity with a new family of porous materials. J. Am. Chem. Soc. 2003, 125, 13370-13371. [CrossRef]

101. Christensen, C.H.; Johannsen, K.; Törnqvist, E.; Schmidt, I.; Topsøe, H.; Christensen, C.H. Mesoporous zeolite single crystal catalysts: Diffusion and catalysis in hierarchical zeolites. Catal. Today 2007, 128, 117-122. [CrossRef]

102. Sun, Y.; Prins, R. Friedel-Crafts alkylations over hierarchical zeolite catalysts. Appl. Catal. A Gen. 2008, 336, 11-16. [CrossRef]

103. Tu, X.; Matsumoto, M.; Maeda, T.; Sugi, Y.; Matsuzaki, T.; Hanaoka, T.; Kubota, Y.; Kim, J.-H. Shape-selective ethylation of biphenyl over a highly dealuminated H-mordenite. Micropor. Mat. 1995, 3, 593-595. [CrossRef]

104. Li, X.; Prins, R.; van Bokhoven, J.A. Synthesis and characterization of mesoporous mordenite. J. Catal. 2009, 262, 257-265. [CrossRef]

105. Jin, L.; Zhou, X.; Hu, H.; Ma, B. Synthesis of 2,6-dimethylnaphthalene by methylation of 2-methylnaphthalene on mesoporous ZSM-5 by desilication. Catal. Commun. 2008, 10, 336-340. [CrossRef]

106. Singh, B.K.; Kim, Y.; Baek, S.B.; Meena, A.; Sultan, S.; Kwak, J.H.; Kim, K.S. Template free facile synthesis of mesoporous mordenite for bulky molecular catalytic reactions. J. Ind. Eng. Chem. 2018, 57, 363-369. [CrossRef]

107. Fu, D.; Paioni, A.L.; Lian, C.; van der Heijden, O.; Baldus, M.; Weckhuysen, B.M. Elucidating Zeolite Channel Geometry-Reaction Intermediate Relationships for the Methanol-to-Hydrocarbon Process. Angew. Chem. Int. Ed. 2020, 59, 20024-20030. [CrossRef]

108. Ma, Q.; Fu, T.; Li, H.; Cui, L.; Li, Z. Insight into the Selection of the Post-Treatment Strategy for ZSM-5 Zeolites for the Improvement of Catalytic Stability in the Conversion of Methanol to Hydrocarbons. Ind. Eng. Chem. Res. 2020, 59, 11125-11138. [CrossRef]

109. Stöcker, M. Methanol-to-hydrocarbons: Catalytic materials and their behavior. Microporous Mesoporous Mater. 1999, 29, 3-48. [CrossRef]

110. Milina, M.; Mitchell, S.; Cooke, D.; Crivelli, P.; Pérez-Ramírez, J. Impact of Pore Connectivity on the Design of Long-Lived Zeolite Catalysts. Angew. Chem. Int. Ed. 2015, 54, 1591-1594. [CrossRef]

111. Erichsen, M.W.; Svelle, S.; Olsbye, U. The influence of catalyst acid strength on the methanol to hydrocarbons (MTH) reaction. Catal. Today 2013, 215, 216-223. [CrossRef]

112. Schulz, H. "Coking" of zeolites during methanol conversion: Basic reactions of the MTO-, MTP- and MTG processes. Catal. Today 2010, 154, 183-194. [CrossRef]

113. Haw, J.F.; Song, W.; Marcus, D.M.; Nicholas, J.B. The Mechanism of Methanol to Hydrocarbon Catalysis. Acc. Chem. Res. 2003, 36, 317-326. [CrossRef]

114. Yan, Y.; Guo, X.; Zhang, Y.; Tang, Y. Future of nano-/hierarchical zeolites in catalysis: Gaseous phase or liquid phase system. Catal. Sci. Technol. 2015, 5, 772-785. [CrossRef]

115. Milina, M.; Mitchell, S.; Crivelli, P.; Cooke, D.; Pérez-Ramírez, J. Mesopore quality determines the lifetime of hierarchically structured zeolite catalysts. Nat. Commun. 2014, 5, 3922. [CrossRef]

116. Li, Y.; Li, L.; Yu, J. Applications of Zeolites in Sustainable Chemistry. Chem 2017, 3, 928-949. [CrossRef]

117. Wang, N.; Sun, W.; Hou, Y.; Ge, B.; Hu, L.; Nie, J.; Qian, W.; Wei, F. Crystal-plane effects of MFI zeolite in catalytic conversion of methanol to hydrocarbons. J. Catal. 2018, 360, 89-96. [CrossRef]

118. Bjørgen, M.; Kolboe, S. The conversion of methanol to hydrocarbons over dealuminated zeolite H-beta. Appl. Catal. A Gen. 2002, 225, 285-290. [CrossRef]

119. Yarulina, I.; Kapteijn, F.; Gascon, J. The importance of heat effects in the methanol to hydrocarbons reaction over ZSM-5: On the role of mesoporosity on catalyst performance. Catal. Sci. Technol. 2016, 6, 5320-5325. [CrossRef]

120. Kim, J.; Choi, M.; Ryoo, R. Effect of mesoporosity against the deactivation of MFI zeolite catalyst during the methanol-tohydrocarbon conversion process. J. Catal. 2010, 269, 219-228. [CrossRef]

121. Schmidt, F.; Hoffmann, C.; Giordanino, F.; Bordiga, S.; Simon, P.; Carrillo-Cabrera, W.; Kaskel, S. Coke location in microporous and hierarchical ZSM-5 and the impact on the MTH reaction. J. Catal. 2013, 307, 238-245. [CrossRef]

122. Ni, Y.; Sun, A.; Wu, X.; Hai, G.; Hu, J.; Li, T.; Li, G. Preparation of hierarchical mesoporous Zn/HZSM-5 catalyst and its application in MTG reaction. J. Nat. Gas Chem. 2011, 20, 237-242. [CrossRef]

123. Wang, X.; Gao, X.; Dong, M.; Zhao, H.; Huang, W. Production of gasoline range hydrocarbons from methanol on hierarchical ZSM-5 and Zn/ZSM-5 catalyst prepared with soft second template. J. Energy Chem. 2015, 24, 490-496. [CrossRef] 
124. Mentzel, U.V.; Højholt, K.T.; Holm, M.S.; Fehrmann, R.; Beato, P. Conversion of methanol to hydrocarbons over conventional and mesoporous H-ZSM-5 and H-Ga-MFI: Major differences in deactivation behavior. Appl. Catal. A 2012, 29, 290-297. [CrossRef]

125. Meng, L.; Zhu, X.; Mezari, B.; Pestman, R.; Wannapakdee, W.; Hensen, E.J.M. On the Role of Acidity in Bulk and Nanosheet [T]MFI $\left(\mathrm{T}=\mathrm{Al}^{3+}, \mathrm{Ga}^{3+}, \mathrm{Fe}^{3+}, \mathrm{B}^{3+}\right)$ Zeolites in the Methanol-to-Hydrocarbons Reaction. ChemCatChem 2017, 9, 3942-3954. [CrossRef] [PubMed]

126. Goodarzi, F.; Herrero, I.P.; Kalantzopoulos, G.N.; Svelle, S.; Lazzarini, A.; Beato, P.; Olsbye, U.; Kegnæs, S. Synthesis of mesoporous ZSM-5 zeolite encapsulated in an ultrathin protective shell of silicate- 1 for MTH conversion. Microporous Mesoporous Mater. 2020, 292, 109730. [CrossRef]

127. Sun, Q.; Wang, N.; Guo, G.; Chen, X.; Yu, J. Synthesis of tri-level hierarchical SAPO-34 zeolite with intracrystalline micro-mesomacroporosity showing superior MTO performance. J. Mater. Chem. A 2015, 3, 19783-19789. [CrossRef]

128. Liu, X.; Ren, S.; Zeng, G.; Liu, G.; Wu, P.; Wang, G.; Chen, X.; Liu, Z.; Sun, Y. Coke suppression in MTO over hierarchical SAPO-34 zeolites. RSC Adv. 2016, 6, 28787-28791. [CrossRef]

129. Jin, W.; Wang, B.; Tuo, P.; Li, C.; Li, L.; Zhao, H.; Gao, X.; Shen, B. Selective Desilication, Mesopores Formation, and MTO Reaction Enhancement via Citric Acid Treatment of Zeolite SAPO-34. Ind. Eng. Chem. Res. 2018, 57, 4231-4236. [CrossRef]

130. Liu, Z.; Ren, S.; Yu, X.; Chen, X.; Wang, G.; Wu, X.; Yu, G.; Qiu, M.; Yang, C.; Sun, Y. Melting-assisted solvent-free synthesis of hierarchical SAPO-34 with enhanced methanol to olefins (MTO) performance. Catal. Sci. Technol. 2018, 8, 423-427. [CrossRef]

131. Valero-Romero, M.J.; Sartipi, S.; Sun, X.; Rodríguez-Mirasol, J.; Cordero, T.; Kapteijn, F.; Gascon, J. Carbon/H-ZSM-5 composites as supports for bi-functional Fischer-Tropsch synthesis catalysts. Catal. Sci. Technol. 2016, 6, 2633-2646. [CrossRef]

132. Dry, M.E. The Fischer-Tropsch process: 1950-2000. Catal. Today 2002, 71, 227-241. [CrossRef]

133. Dry, M.E. High quality diesel via the Fischer-Tropsch process-A review. J. Chem. Technol. Biotechnol. 2001, 77, 43-50. [CrossRef]

134. Sadek, R.; Chalupka, K.A.; Mierczynski, P.; Rynkowski, J.; Gurgul, J.; Dzwigaj, S. Cobalt Based Catalysts Supported on Two Kinds of Beta Zeolite for Application in Fischer-Tropsch Synthesis. Catalysts 2019, 9, 497. [CrossRef]

135. Davis, B.H. Fischer-Tropsch Synthesis: Comparison of Performances of Iron and Cobalt Catalysts. Ind. Eng. Chem. Res. 2007, 46, 8938-8945. [CrossRef]

136. Carvalho, A.; Marinova, M.; Batalha, N.; Marcilio, N.R.; Khodakov, A.Y.; Ordomsky, V.V. Design of nanocomposites with cobalt encapsulated in the zeolite micropores for selective synthesis of isoparaffins in Fischer-Tropsch reaction. Catal. Sci. Technol. 2017, 7, 5019-5027. [CrossRef]

137. Liu, R.-J.; Xu, Y.; Qiao, Y.; Li, Z.-H.; Ma, X.-B. Factors influencing the Fischer-Tropsch synthesis performance of iron-based catalyst: Iron oxide dispersion, distribution and reducibility. Fuel Process. Technol. 2015, 139, 25-32. [CrossRef]

138. Kang, J.; Cheng, K.; Zhang, L.; Zhang, Q.; Ding, J.; Hua, W.; Lou, Y.; Zhai, Q.; Wang, Y. Mesoporous Zeolite-Supported Ruthenium Nanoparticles as Highly Selective Fischer-Tropsch Catalysts for the Production of $\mathrm{C}_{5}-\mathrm{C}_{11}$ Isoparaffins. Angew. Chem. Int. Ed. 2011, 50, 5200-5203. [CrossRef]

139. Wang, S.; Yin, Q.; Guo, J.; Ru, B.; Zhu, L. Improved Fischer-Tropsch synthesis for gasoline over Ru, Ni promoted Co/HZSM-5 catalysts. Fuel 2013, 108, 597-603. [CrossRef]

140. Plana-Pallejà, J.; Abelló, S.; Berrueco, C.; Montané, D. Effect of zeolite acidity and mesoporosity on the activity of Fischer-Tropsch Fe/ZSM-5 bifunctional catalysts. Appl. Catal. A Gen. 2016, 515, 126-135. [CrossRef]

141. Xing, C.; Yang, G.; Wu, M.; Yang, R.; Tan, L.; Zhu, P.; Wei, Q.; Li, J.; Mao, J.; Yoneyama, Y.; et al. Hierarchical zeolite Y supported cobalt bifunctional catalyst for facilely tuning the product distribution of Fischer-Tropsch synthesis. Fuel 2015, 148, 48-57. [CrossRef]

142. Peng, X.; Cheng, K.; Kang, J.; Gu, B.; Yu, X.; Zhang, Q.; Wang, Y. Impact of Hydrogenolysis on the Selectivity of the FischerTropsch Synthesis: Diesel Fuel Production over Mesoporous Zeolite-Y-Supported Cobalt Nanoparticles. Angew. Chem. Int. Ed. 2015, 54, 4553-4556. [CrossRef]

143. Zhao, W.; Wang, Y.; Li, Z.; Wang, H.; Wu, J.; Huang, J.; Zhao, Y. The influence of hierarchical zeolite composition and pore structure on behavior of cobalt-based Fischer-Tropsch synthesis catalysts. J. Porous Mater. 2015, 22, 1097-1104. [CrossRef]

144. Sartipi, S.; Parashar, K.; Makkee, M.; Gascon, J.; Kapteijn, F. Breaking the Fischer-Tropsch synthesis selectivity: Direct conversion of syngas to gasoline over hierarchical Co/H-ZSM-5 catalysts. Catal. Sci. Technol. 2012, 3, 572. [CrossRef]

145. Kim, J.-C.; Lee, S.; Cho, K.; Na, K.; Lee, C.; Ryoo, R. Mesoporous MFI Zeolite Nanosponge Supporting Cobalt Nanoparticles as a Fischer-Tropsch Catalyst with High Yield of Branched Hydrocarbons in the Gasoline Range. ACS Catal. 2014, 4, 3919-3927. [CrossRef]

146. Liang, J.; Liang, Z.; Zou, R.; Zhao, Y. Heterogeneous catalysis in zeolites, mesoporous silica, and metal-organic frameworks. Adv. Mater. 2017, 29, 1701139. [CrossRef]

147. Sudarsanam, P.; Peeters, E.; Makshina, E.V.; Parvulescu, V.I.; Sels, B.F. Advances in porous and nanoscale catalysts for viable biomass conversion. Chem. Soc. Rev. 2019, 48, 2366-2421. [CrossRef]

148. Arias, K.S.; Climent, M.J.; Corma, A.; Iborra, S. Two-dimensional itq-2 zeolite for biomass transformation: Synthesis of alkyl 5-benzyl-2-furoates as intermediates for fine chemicals. ACS Sustain. Chem. Eng. 2016, 4, 6152-6159. [CrossRef]

149. Quispe, C.A.G.; Coronado, C.J.R.; Carvalho, J.A. Glycerol: Production, consumption, prices, characterization and new trends in combustion. Renew. Sustain. Energy Rev. 2013, 27, 475-493. [CrossRef]

150. Vasiliadou, E.S.; Heracleous, E.; Vasalos, I.A.; Lemonidou, A.A. Ru-based catalysts for glycerol hydrogenolysis-Effect of support and metal precursor. Appl. Catal. B Environ. 2009, 92, 90-99. [CrossRef] 
151. Bagheri, S.; Julkaplin, N.M.; Yehye, W.A. Catalytic conversion of biodiesel derived raw glycerol to value added products. Renew. Sustain. Energy Rev. 2015, 41, 113-127. [CrossRef]

152. Miyazawa, T.; Kusunoki, Y.; Kunimori, K.; Tomishige, K. Glycerol conversion in the aqueous solution under hydrogen over Ru/C plus an ion-exchange resin and its reaction mechanism. J. Catal. 2006, 240, 213-221. [CrossRef]

153. Nakagawa, Y.; Tomishige, K. Heterogeneous catalysis of the glycerol hydrogenolysis. Catal. Sci. Technol. 2011, 1, 179-190. [CrossRef]

154. Zhou, C.-H.; Beltramini, J.N.; Fan, Y.-X.; Lu, G.Q. Chemoselective catalytic conversion of glycerol as a biorenewable source to valuable commodity chemicals. Chem. Soc. Rev. 2008, 37, 527-549. [CrossRef]

155. Singh, B.K.; Kim, Y.; Kwon, S.; Na, K. Selective Catalytic Transfer Hydrogenolysis of Glycerol to 2-Isopropoxy-Propan-1-Ol over Noble Metal Ion-Exchanged Mordenite Zeolite. Catalysts 2019, 9, 885. [CrossRef]

156. Beerthuis, R.; Huang, L.; Shiju, N.R.; Rothenberg, G.; Shen, W.; Xu, H. Facile Synthesis of a Novel Hierarchical ZSM-5 Zeolite: A Stable Acid Catalyst for Dehydrating Glycerol to Acrolein. ChemCatChem 2018, 10, 211-221. [CrossRef]

157. Possato, L.; Diniz, R.; Garetto, T.; Pulcinelli, S.; Santilli, C.; Martins, L. A comparative study of glycerol dehydration catalyzed by micro/mesoporous MFI zeolites. J. Catal. 2013, 300, 102-112. [CrossRef]

158. Gonzalez-Arellano, C.; Grau-Atienza, A.; Serrano, E.; Romero, A.A.; Garcia-Martinez, J.; Luque, R. The role of mesoporosity and $\mathrm{Si} / \mathrm{Al}$ ratio in the catalytic etherification of glycerol with benzyl alcohol using ZSM-5 zeolites. J. Mol. Catal. A Chem. 2015, 406, 40-45. [CrossRef]

159. Xiao, W.; Wang, F.; Xiao, G. Performance of hierarchical HZSM-5 zeolites prepared by NaOH treatments in the aromatization of glycerol. RSC Adv. 2015, 5, 63697-63704. [CrossRef]

160. Gustavsson, L.; Haus, S.; Lundblad, M.; Lundström, A.; Ortiz, C.A.; Sathre, R.; Truong, N.L.; Wikberg, P.-E. Climate change effects of forestry and substitution of carbon-intensive materials and fossil fuels. Renew. Sustain. Energy Rev. 2017, 67, 612-624. [CrossRef]

161. McKechnie, J.; Colombo, S.; Chen, J.; Mabee, W.; MacLean, H.L. Forest bioenergy or forest carbon? Assessing trade-offs in greenhouse gas mitigation with wood-based fuels. Environ. Sci. Technol. 2011, 45, 789-795. [CrossRef]

162. Abbasi, T.; Abbasi, S.A. Decarbonization of fossil fuels as a strategy to control global warming. Renew. Sustain. Energy Rev. 2011, 15, 1828-1834. [CrossRef]

163. Aresta, M.; Dibenedetto, A.; Angelini, A. Catalysis for the valorization of exhaust carbon: From $\mathrm{CO}_{2}$ to chemicals, materials, and fuels. Technological use of $\mathrm{CO}_{2}$. Chem. Rev. 2014, 114, 1709-1742. [CrossRef]

164. Najafabadi, A.T. $\mathrm{CO}_{2}$ chemical conversion to useful products: An engineering insight to the latest advances toward sustainability. Int. J. Energy Res. 2013, 37, 485-499. [CrossRef]

165. Li, C.-G.; Xu, L.; Wu, P.; Wu, H.; He, M. Efficient cycloaddition of epoxides and carbon dioxide over novel organic-inorganic hybrid zeolite catalysts. Chem Comm 2014, 50, 15764-15767. [CrossRef]

166. Kim, D.; Na, K. Organic-inorganic multifunctional hybrid catalyst giving catalytic synergies in cooperative coupling between $\mathrm{CO}_{2}$ and propylene oxide to propylene carbonate. J. $\mathrm{CO}_{2}$ Util. 2018, 27, 129-136. [CrossRef]

167. Sattler, J.J.H.B.; Ruiz-Martinez, J.; Santillan-Jimenez, E.; Weckhuysen, B.M. Catalytic dehydrogenation of light alkanes on metal and metal oxides. Chem. Rev. 2014, 114, 10613-10653. [CrossRef]

168. Ryoo, R.; Kim, J.; Jo, C.; Han, S.W.; Kim, J.-C.; Park, H.; Han, J.; Shin, H.S.; Shin, J.W. Rare-earth-platinum alloy nanoparticles in mesoporous zeolite for catalysis. Nature 2020, 585, 221-224. [CrossRef]

169. Han, S.W.; Park, H.; Han, J.; Kim, J.-C.; Lee, J.; Jo, C.; Ryoo, R. PtZn intermetallic compound nanoparticles in mesoporous zeolite exhibiting high catalyst durability for propane dehydrogenation. ACS Catal. 2021, 11, 9233-9241. [CrossRef] 